\title{
Design and commission of an experimental test rig to apply a full-scale pressure load on composite sandwich panels representative of aircraft secondary structure

\author{
D A Crump ${ }^{1}$, J M Dulieu-Barton ${ }^{1}$, J Savage ${ }^{2}$ \\ Southampton, SO17 1BJ, UK \\ ${ }^{2}$ GE Aviation, Kings Avenue, Hamble-Le-Rice, Hampshire, SO31 4NF, UK
} \\ ${ }^{1}$ School of Engineering Sciences, University of Southampton, Highfield, \\ E-mail: janice@soton.ac.uk
}

\begin{abstract}
This paper describes the design of a test rig to apply a representative pressure load to full-scale composite sandwich secondary aircraft structure. A generic panel was designed with features to represent those in composite sandwich secondary aircraft structure. To provide full-field strain data from the panels, the test rig was designed for use with optical measurement techniques such as thermoelastic stress analysis (TSA) and digital image correlation (DIC). TSA requires a cyclic load to be applied to a structure for the measurement of the strain state, therefore the test rig has been designed to be mounted on a standard servo-hydraulic test machine. As both TSA and DIC require an uninterrupted view of the surface of the test panel, an important consideration in the design is facilitating the optical access for the two techniques. To aid the test rig design a finite element (FE) model was produced. The model provides information on the deflections that must be accommodated by the test rig, and ensures the stress and strain levels developed in the panel when loaded in the test rig would be sufficient for measurement using TSA and DIC. Finally, initial tests using the test rig have shown it to be capable of achieving the required pressure and maintaining a cyclic load. It was also demonstrated that both TSA and DIC data can be collected from the panels under load, which is used to validate the stress and deflection derived from the FE model.
\end{abstract}

Keywords: Pressure loading, Full-field optical strain measurement techniques, Composite structure, Full-scale testing

\section{Introduction}

The recent increased use of composite sandwich structure in airframe construction has resulted in significant weight reduction; e.g. the Airbus A380 structure is made up of 22\% from composites by weight, while the Boeing 787 is expected to be made from 50\% composite structure [1]. However, the reduction in weight comes at a cost premium, as the production methods associated with the 
manufacture of composite parts are very expensive [2, 3]. A great deal of research [4-7] has been conducted on the optimisation of production methods for the use of composites in primary aircraft structure, however there is little work reported on secondary structure. This paper examines carbon fibre sandwich panels that are used as 'gap fillers' on the wing leading and trailing edges. Such panels are of sandwich construction made from face sheets of layers of pre-impregnated (pre-preg) carbon fibres and a Nomex honeycomb core. The sandwich panels are produced by hand lay-up before being consolidated and cured in an autoclave. The inherent disadvantages of the hand layup/autoclave process have been discussed $[2,8]$. The process is heavily dependent upon labour and the production of the face sheets requires a vacuum debulk after each layer of prepreg is introduced. The autoclave introduces large capital and running costs $[3,9]$. It has also been shown that the use of an autoclave, which is a batch process, forms a large bottleneck in the flow of the manufacturing process [3]. It is therefore advantageous to remove the autoclave consolidation from the process. It is also desirable to reduce the number of plies in the face sheets to reduce the number of debulks. It has been shown in previous work by the authors that significant savings are made if a resin film infusion is used [3]. This requires only an oven consolidation, which removes the autoclave and reduces the production bottleneck. The fibre mats used in this process are supplied in stitched layers of four plies of material. Resin film is introduced between the layers and this reduces the number of vacuum debulks from 11 to 2, resulting in a decrease in total manufacturing time from 29 to 20 hours. Therefore, the resin-film infusion process is a prime candidate as an alternative manufacturing option for secondary structure panels.

Before accepting the resin-film infusion process as the manufacturing technique for the secondary panels, it is essential to examine the performance of the material and characterise the material properties. The latter was carried out in previous work [3], and it was shown that the face sheet material elastic, flexural and strength properties were practically identical for both manufacturing processes. However the through-thickness properties were slightly reduced for resin film infusion. These tests were carried out on coupons cut from flat panels of the face sheet material. In practice the materials will be employed in a sandwich panel and therefore to fully assess the performance of the material some full scale tests are required. This presents a challenging proposition, as the service load is a uniform pressure load across the surface of the panel; significant innovation is required to accommodate this properly in the test rig design. Furthermore, since the stress in the panels is not uniform, point readings from strain gauges are not sufficient and instead full-field techniques such as thermoelastic stress analysis (TSA) [10] and digital image correlation (DIC) [11] should be employed. Both these techniques require the surface of the panels to be optically accessible, providing a further challenge for the test rig design. It might be considered prudent at this stage to conduct some tests on sandwich beams, perhaps in three and four point bending. However, these types of tests require 
contact between the face sheet and the loading points. Deformation at the contact points needs to be controlled and this can lead to spurious results. Furthermore it is difficult (although not impossible) to gain optical access to the face sheet to apply optical techniques. Moreover beams and 'plates' behave in different ways and it is not always possible to link the behaviour of the two. Therefore this work concentrates on the panel testing.

The purpose of this paper is to describe the design and commissioning of a full-scale test rig that mimics in-service pressure loading on secondary structure panels. A description of in-service loading on secondary structure panels is provided along with a brief description of the construction of the panels. This is followed by a description of the development of the test rig design from concept to application. A FE model of the panels under the service load is used to inform the design of the rig; full details of the model are provided. Finally, the application of full-field measurement techniques is described, along with a validation of the FE models based on the data from the DIC and TSA.

\section{Design of Generic Test Panels}

Secondary sandwich structure access panels on the leading and trailing edges of the wing of mid-sized commercial aircraft form part of the skin structure of the wing but have no primary load bearing function. They are classed as 'gap fillers' between the main wing structure and the flaps, ailerons, etc. Figure 1 shows a schematic diagram of a wing from a mid-sized commercial passenger aircraft where the secondary structure panels are shaded in grey. The panels are connected to the wing substructure, and in the worst case scenario, such panels may be supported on only three sides, fastened to the wing structure with rivets. The primary structure is designed to withstand the flight load; the secondary structure forms only a 'skin' around the primary structure. Therefore, the secondary panels do not need to withstand any loads imparted by the weight of the structure or thrust from the engines, takeoff, landing or manoeuvring of the aircraft. Instead, the panels need only withstand aerodynamic loading on their surface during flight. The aerodynamic loading has been shown to correspond to a pressure load of $21 \mathrm{kPa}$ [12] across the surface of the panels. In the design the bending load on the wing is neglected and only the pressure load is used in the design process. Therefore in this work the $21 \mathrm{kPa}$ pressure load is regarded as the limit load the panel must be able to withstand without suffering detrimental permanent deformation or interfering with the operation of the aircraft [13]. It should also be considered that depending on the position of the panel the pressure load could be positive or negative.

A review of previous designs of Carbon Fibre Reinforced Polymer (CFRP) face sheet/honeycomb core sandwich structure was undertaken, which provided information on typical panels used for wing 
secondary structures. The review identified a number of 'common' features, as follows:

- Face sheets are of quasi-isotropic lay-up with 12 plies at $0.125 \mathrm{~mm}$ per ply,

- Panels are long and narrow - between 700 and $1500 \mathrm{~mm}$ long by 300 wide,

- Cut-outs and notches are used to account for neighbouring structure,

- Inserts and solid pucks are used for attachments,

- Simplistic block-like core geometry.

To assess the full-scale performance of sandwich panels manufactured using different processes, a generic panel was designed to be representative of secondary structure panels by considering the points above [3]. Features such as inserts, attachments, cut-outs and notches were set-aside, as these would lead to stress concentrations that are dependent on the ply lay-up and orientation, hence detracting from a straightforward evaluation of the manufacturing processes. The relatively simple geometry of the generic panel is shown in Figure 2. It is flat and has a plan area of $0.9 \mathrm{~m} \times 0.3 \mathrm{~m}$. The honeycomb core is $0.6 \mathrm{~m} \mathrm{x} 0.2 \mathrm{~m}$ and $12.5 \mathrm{~mm}$ thick. A non-core stiffened flange is included as it is a key feature in such panels and is essential for attachment purposes. The flange has a total cured thickness of approximately $3 \mathrm{~mm}$, half formed by the tool-side face sheet, and half by the bag-side face sheet. The flange contains 19 holes of $7 \mathrm{~mm}$ on three of its sides. This models the attachment to the airframe and facilitates attachment to the experimental rig in the full-scale tests.

Generic panels were manufactured from two materials: Material 1 (M1) is a unidirectional (UD) prepreg that was autoclave cured. The individual layers of prepreg are $0.125 \mathrm{~mm}$ thick, therefore 12 layers were required to form the $1.5 \mathrm{~mm}$ thick face sheets. Material 2 (M2) is dry non-crimp fabric with separate resin film and cured in a conventional oven. Each layer of the dry fabric contains four UD plies stitched together in a QI configuration, therefore only 3 layers were required to form face sheet.

Before considering the test rig design, it was essential that the effect of the pressure load on the composite sandwich generic panels was estimated. Without this information it would have been impossible to establish if there was sufficient space around the rig to accommodate the deformation of the panels. For this reason, a Finite Element (FE) model of the generic panel made from M1 was produced to provide an estimation of the deformations and stresses to be expected during loading. The FE model was constructed using ANSYS 11 (ANSYS Inc, Canonsburg, USA). Firstly, the flange region of the panel was constructed to include the plies of both the mould side and bag side face sheets. Then the core was constructed by setting the size of the core that is touching the mould side face sheet and extruding in the z-direction (as shown in Figure 2). The chamfer on the core was produced by tapering in the $\mathrm{x}$ and $\mathrm{y}$ direction. The model was completed by adding the mould side face sheet plies to the base of the core volume and the bag-side face sheet plies to the areas on the top of the core. 
The core was assumed to be a single anisotropic solid volume with material properties as given in Table 1; it was modelled using eight node brick elements (Solid185) of 0.01 x 0.01 x $0.01 \mathrm{~m}$. The carbon fibre face sheets were modelled using Shell181; a four node element suitable for producing layered FE models. The element can accommodate large linear rotations and large nonlinear strains, hence enabling the out-of-plane displacement of the panel to be derived. The ability of the element to allow a layered construction is also essential as this enabled the generation of a ply-by-ply model of the face sheets. The flange of the model comprises both the mould and the bag side face sheet and contained 24 layers, whilst the face sheets surrounding the core had 12 plies each. This construction follows identically the construction of the generic panels using the autoclave and prepreg manufacturing process, M1. Therefore the material properties, given in Table 1, for the autoclaved cured material were used in the model. The fibre orientation was maintained on the angled edges of the core by altering the individual element coordinate systems such that $\mathrm{z}$ remained perpendicular to the surface.

The fixings in the flange of the generic panel generated the added complexity of contact and stress concentration. It was considered at this stage in the design process that these should be omitted from the model. Therefore the service constraints were represented by imposing zero deflection on three edges of the model; i.e. the two short edges and one of the longer edges. With such boundary conditions, the model is constrained in all degrees of freedom along three edges, whilst the free edge has six degrees of freedom. The pressure load of $21 \mathrm{kPa}$ was applied to the model by applying a force perpendicular to each of the 2150 surface nodes. The pressure equates to a load of $1.92 \mathrm{~N}$ per node. The model has a relatively low thickness in comparison to its length and width, and was subjected to an out-of-plane pressure load that induced relatively large deflections. For this reason the model was solved using a geometrically nonlinear solver. The size of elements was altered from a starting point of $0.1 \mathrm{~m}$ and reduced, estimating the maximum displacement each time. As the element size was altered the maximum displacement converged on one value, as shown in Figure 3, demonstrating that the model estimation was correct. From this convergence curve an element size of $0.01 \mathrm{~m}$ was chosen. This choice was a compromise between processing time and resolution, as using smaller elements would have increased the spatial resolution but at a cost of much longer run times.

Figure 4 shows the FE mesh alongside a contour plot of the deflection of the model when subjected to the service load of $21 \mathrm{kPa}$. The model generated a maximum deflection, on the free edge, of approximately $10 \mathrm{~mm}$. The rig was therefore designed to accommodate the panel deformation estimation allowing a safety factor for inaccuracies in the model and 'over-loading'. The model also provided an estimate of the stresses and in-plane strains in the panel under pressure loading. The predicted peak stress was around $200 \mathrm{MPa}$, and the in-plane strains ranged between -3000 and 3000 $\mu$ strain. If the use of full-field optical measurement techniques is to be successful for these tests, the 
expected response from the panel must be greater than the resolution of each technique. The resolution of TSA is heavily dependent upon the infra-red detector. The Cedip Silver 480M system used in this work has a thermal resolution of between 6 and $10 \mathrm{mK}$ and can detect temperature changes of less if using the lock-in features required for TSA. For carbon fibre/epoxy composites this means a stress resolution of about $2 \mathrm{MPa}$ for the transverse direction. The LaVision DIC system used in this work is capable of measuring in-plane strains of $220 \mu$ strain as quoted by the manufacturer for a 128 x 128 cell size with a 50\% overlap (for more details see section 6.1). Therefore, the suggested geometry and construction of the generic panels is suitable for analysis with the TSA and DIC techniques.

\section{Concept Design of Test Rig}

To replicate the in-service loading conditions on the secondary structure panels it was necessary to construct a test rig. As the behaviour of the generic panels will be complex, with non-uniform stress and strain, it was decided that rather than just obtaining simple load deflection data from the loaded panels it would be much more informative to generate full-field strain data. The proposed techniques for full-field analysis are TSA and DIC, which are both optical techniques. Therefore the test rig must allow an uninterrupted view of the surface of the generic panels for the optical techniques to be applied successfully.

To facilitate the necessary cyclic load for the use of TSA a standard Instron servo-hydraulic test machine 8802 (Instron, High Wycombe, UK) was used as the basis for the loading rig. The load frame of Instron's 8802 is free-standing and floor mounted and has a working volume of up to approximately $640 \mathrm{~mm}$ wide by $1500 \mathrm{~mm}$ tall and $300 \mathrm{~mm}$ deep, although this can be increased if the specimen is allowed to extend over the machine's base. The hydraulic system is capable of applying a load of $100 \mathrm{kN}$, and its frame, which is rated to $200 \mathrm{kN}$, forms a rigid bed for mounting the rig. To replicate the in-service loading, the test rig must be capable of imparting a pressure load across the mould side surface of the generic panels. To obtain the pressure load a fully constrained fluid filled flexible cushion was employed. The pressure load is developed by clamping the panels on three edges and pulling the clamped panel over the flexible cushion. The concept is shown in Figure 5 in both the unloaded and loaded conditions. By fully constraining the cushion the pressure load inside the cushion can be fully transferred into the test panels. To minimise compressibility, and for safety reasons, the cushion working fluid is water. Previous work has demonstrated that a water filled flexible cushion can be used to apply a pressure load across the surface of a composite sandwich panel [14] and enable a static load to be applied. However, in this work it is envisaged that by attaching the rig to a servo-hydraulic test machine it would be possible to apply a cyclic pressure load to a panel, facilitating the use of TSA. Furthermore because of the constraint on the flexible cushion it is 
envisaged that the load across the mould side face sheet will be uniform. In practice the pressure load will be negative on the mould side face sheet as it is shown in Figure 1. However, for the current rig proof of concept positive pressure loading on the mould side provided the least complex scenario and at this stage was considered to be acceptable.

The initial concept for the loading rig is shown in Figure 6 whilst Figure 7 shows a photograph of the rig in-situ. It comprises essentially of four components:

- The servo-hydraulic test machine, shown in light grey

- The fixed support structure, shown in dark grey (i.e. the parts painted yellow in Figure 7)

- $\quad$ The moving loading structure, shown in white (i.e. the parts painted red in Figure 7)

- The generic panel, shown in black

The fixed structure houses the flexible cushion and has negligible deformation during loading to ensure full load transfer between the flexible cushion and test panel. The fixed structure was constructed of steel box section that supports a steel plate, upon which the flexible cushion is mounted (see Figure 5). The fixed construction is attached to both the pillars and the feet of the test machine. The generic panel is bolted to the moving section. The moving section is mounted in the lower grips of the test machine, which are attached to the actuator. The actuator moves down and the panel is pulled over the flexible cushion imparting a pressure load to the cushion that is transferred to the test panel. The optical devices are positioned directly above the panel to provide a plan view of the stress/strain field in the panel. The design has the benefit that there are no loading shackles acting as detractors in the field of view. However, there is not a load cell in the loading chain, hence it is necessary to monitor the applied load or pressure using a pressure transducer attached to the flexible cushion; the cushion and pressure transducer are therefore effectively acting as a load cell.

\section{Detailed Design of Rig}

\subsection{Flexible pressure cushion:}

The pressurised part of the pressure rig design concerns the flexible cushion, and methods to pressurise and monitor the pressure within the cushion. The water cushion was specified to withstand internal pressures of $345 \mathrm{kPa}$ and was manufactured by Flexitec (Flexitec Structures Ltd, Fareham, $U K)$. The cushion is made from polyurethane, and must be fully constrained when pressurised. It was designed to fit neatly into the rig taking the geometry of the space between the support plate and the panel (see Figure 6). A hand pump was attached to enable initial pressurisation to a mean level and hence allow a greater range of pressures to be imparted by the water cushion. The cushion also has 
two push fittings; one to pressurise, using the hand pump, and the second connected to a pressure transducer. The pressure transducer, model 07356-02 from Cole Parmer (Cole Parmer Instrument Company Ltd, London, UK), has a full range of 60 psi gauge pressure with an accuracy of $1 \%$ and provides an electrical output of 1-5 Vdc. The end of the transducer containing the measurement diaphragm is screwed into a flexible pipe directly connected to the base of the water cushion. The other end of the transducer has a 9-pin D connector and is plugged into a high-level card on a Vishay Strainsmart 6200A scanner which calibrates the electrical signal and records the pressure values.

\subsection{Fixed structure:}

The fixed support structure takes the form of a table, and fits around the Instron test machine without interfering with the operation of the moving part of the rig. The construction is mainly of steel box section. The legs of the fixed part were designed to connect to the feet of the test machine. As the load through the structure is always compressive it was possible to use a simple pin configuration for the attachment without the need for mechanical fasteners as shown in Figure 6. The structure consisted of two separate sections each with two legs topped by the upper transverse beams (see Figure 6) which are welded to the two legs. The leg sections were additionally stiffened by transverse members closer to the feet. The two sections are connected by the 'connecting beams' (see Figure 6). The connecting beams were also fixed to the pillars of the test machine. The longitudinal beams that support the steel plate upon which the pressurised cushion is mounted are attached using bolts when the rest of fixed structure is assembled on the test machine. The pressure bag must be fully enclosed while pressurised, and therefore the fourth edge that is not enclosed by the moving part must be closed. The final section of the fixed part is therefore a tall box section that is mounted on one side of the steel plate as shown in Figure 6.

Once the design of the fixed part had been finalised it was important to investigate if it would remain rigid under operation. For this reason the fixed part was modelled using FE software ANSYS 11. The model was constructed with solid elements using a cross-section with the same second moment of area as a box section to simplify the model. A load of $345 \mathrm{kPa}$, i.e. ten times greater than that used in the testing, was applied to the model to provide an adequate safety factor. The table structure was assumed to be constrained at the base of each leg in all degrees of freedom and the load imparted on the top surface of the metal support plate as a pressure load. The maximum deformation was calculated as $2.55 \mathrm{~mm}$, at an unsupported edge of the water cushion support plate, under the $345 \mathrm{kPa}$ pressure loading. This was not considered to be significant when considering the scale of the rig, so it was concluded that this part of the rig design was of suitable construction to carry the loads developed during testing. 


\subsection{Moving structure:}

The moving part is connected to the actuator of the test machine at one end, and bolted to the test panel at the other. The movement of the actuator pulls the test panel over the fully supported pressurised cushion and imparts the load. The top of the moving part was formed from three sections of solid steel. One section is the length of the moving part, while the other two form the front and rear of the top part. These three sections were bolted together during manufacture and were not designed to be dismantled. The top section of the moving part is mounted on the two vertical sides formed from solid steel sections, which contained lightening holes. The sides were attached to the top with pins, which, again, were not designed to be dismantled. Finally, a solid section sits between the vertical sides at their base with a pin protruding from its base for attachment to the test machine. The standard hydraulic grips supplied with the test machine were used to secure the moving structure to the test machine. The moving part had a circular cross section pin of diameter $17 \mathrm{~mm}$ machined into it to accommodate this fixing. In the upper part of the moving structure 19 tapped holes were machined so that the test panel can be fixed to the structure. It was considered that loading through tapped holes was not ideal but it was not practical to achieve the loading in any other way. To spread the load more evenly in the flange, penny washers were used under each bolt head.

The moving part was modelled using ANSYS 11 to confirm that it was practically rigid under operational loads. The model of the moving part was constrained along the top perimeter where the generic panel is held and a tension load applied to the base of the circular section that is accommodated in the grips attached to the actuator of the test machine. The maximum deformation was calculated $0.68 \mathrm{~mm}$, on the fourth side to which the generic panel is not bolted, under the maximum load. Again this was not deemed to be significant, and under the expected 'service' loads the rig can be considered 'rigid'.

\subsection{Finalising the design:}

The pressure fittings, water inlet and transducers, are attached to the bottom of the water cushion and therefore must pass through the steel supporting plate. Two holes were drilled into the supporting plate to allow this. Pipes connecting to these pressure fittings then pass between the two vertical sides of the moving part of the rig (see Figure 6). These pipes are flexible hydraulic hoses, and therefore were routed around the rigid sections of the rig.

The results of the FE model of both structural parts of the test rig demonstrated that the rig will not deform significantly under load. Therefore, the pressure within the water cushion will be completely transferred to the generic panel. The results of the FE model also provided the stress data that allowed 
the selection of the grade of steel to be used to manufacture the rig. The steel chosen for the manufacture was EN8 medium carbon steel that has a yield stress of $530 \mathrm{MPa}$, which is higher than the maximum stresses predicted by the FE.

\section{Commissioning of the Test Rig}

Figure 7 shows two photographs of the rig installed on the test machine; the moving structure has been painted red, and therefore in print will appear dark grey, and the fixed structure has been painted yellow, and therefore appears as a lighter grey. The first image shows the entire rig structure and the second shows the rig with a view of the generic panel from the same projection as shown in Figure 6.

The commissioning began with static tests that applied a variety of pressures to the panel and ensured the rig could achieve and maintain the required pressures. The water cushion was filled with water such that it has a pressure of $0 \mathrm{kPa}$ gauge. The test machine actuator was manually moved downward and therefore applied an increasing pressure. The applied pressure was monitored using the Vishay Strainsmart 6200A system. During these tests the out-of-plane displacement was independently measured using a LVDT displacement transducer located on the free edge of the generic panel approximately $160 \mathrm{~mm}$ from the front. This coincided with the point that was expected to undergo the maximum out-of-plane deformation. Three static tests were performed, increasing the maximum applied pressure in each. The pressure was initially ramped to $13.8 \mathrm{kPa}(2 \mathrm{psi})$ then to $20.7 \mathrm{kPa}(3$ psi) and finally to $27.6 \mathrm{kPa}$ (4 psi). Figure 8a plots the maximum out-of-plane displacement against the applied pressure for each of the three tests. Figure 8a shows that for all three loading cases the displacement of the panel is virtually linearly related to the applied pressure. Importantly the plots from the three tests show the same slope demonstrating that the rig is capable of providing a consistent loading and the viability of the rig for static loading and application of DIC.

For an applied pressure of $10.3 \mathrm{kPa}$ the measured out-of-plane deformation recorded with the LVDT was $7.2 \mathrm{~mm}$ whilst the FE model predicted $7.7 \mathrm{~mm}$. The excellent correspondence between these results, with a difference of approximately only $7 \%$, provides an important initial validation of the FE model.

During testing the pressure is controlled using the position controller of the test machine, so it was vital to establish the relationship between the position value indicated by the test machine and the applied pressure measured by the pressure transducer. Therefore, during the static tests the position of the test machine actuator was recorded at each pressure value as shown in Figure 8b. The pressure increases linearly with test machine position, except for pressure values below $3.45 \mathrm{kPa}(0.5 \mathrm{psi})$. It is considered that this initial nonlinear relationship between the actuator position and pressure is due to initial 'slack' in the loading rig due to clearances in fittings and some flexibility in the rig. The results 
of these tests show that to increase the applied pressure by $6.9 \mathrm{kPa}$ ( 1 psi) requires an actuator movement of approximately $4.5 \mathrm{~mm}$. However, there is some discrepancy between the gradients of the displacement and position against pressure curves, as Figure 8a, shows a pressure of $6.9 \mathrm{kPa}$ will produce a displacement of approximately $4.1 \mathrm{~mm}$ in the panel. The cause of the discrepancy can be attributed to the compressibility of water and the actuator oil as well as possible measurement error in the values obtained from the LVDT and the test machine displacement transducer (both of the order of $\pm 0.1 \mathrm{~mm})$.

As TSA requires a cyclic load, it is also necessary to demonstrate the capability of the rig to impart a consistent cyclic pressure into the panels. In cyclic loading the pressure must be controlled by the servo-hydraulic machine position control facilities. Therefore the information produced in the static tests was used to determine the applied displacement range necessary to achieve a certain pressure range in the panel. The actuator was moved manually by controlling the position until the applied pressure recorded $2 \mathrm{kPa}$. A $3 \mathrm{~mm}$ displacement range was applied around the mean pressure of $2 \mathrm{kPa}$ at frequencies of 1 and $2 \mathrm{~Hz}$. According to Figure 8b this should result in an applied pressure range of $5.2 \mathrm{kPa}(0.75 \mathrm{psi})$. Figure 9 shows the profile of the cyclic pressure for both loading frequencies. It can be seen that at $1 \mathrm{~Hz}$ the cyclic pressure range is $5.2 \mathrm{kPa}$ and at $2 \mathrm{~Hz}$ the cyclic pressure range is 5 $\mathrm{kPa}$. The plots in Figure 9 show the pressure range is well maintained repeatedly cycle after cycle for both loading frequencies. It should be noted that the small reduction in the pressure range achieved for the higher frequency is entirely consistent with what is expected from a standard test machine. The important feature here is that the pressure cushion set-up can apply and maintain a viable cyclic sinusoidal load that is suitable for TSA.

\section{Application of full field measuring techniques}

\subsection{Digital Image Correlation (DIC):}

Digital Image Correlation (DIC) has been used successfully for analysis of heterogeneous engineering materials such as composites [15]. DIC tracks the surface displacements of deformed structure by recognition of geometrical changes in grey scale distribution of surface patterns before and after a strain has been applied [15]. The system used in the present work comprised two digital cameras with 2 MPixel resolution that allow three-dimensional analysis of the deformations and measurement of the in-plane strains. The images are recorded and processed using DaVis 7.2 produced by LaVision. This system must be calibrated before it is used to produce a 'working volume', in which the surface height of the specimen from a known plane can be calculated. The processing of the images can be controlled by selecting optimum combinations of the two main processing parameters; cell size and cell overlap. An important part of the current work is to study the effect of altering these parameters. 
All that is required for DIC analysis is an unstrained (reference) image and a strained (deformed) image that can be compared to the reference image [16]. The reference image is divided into 'cells' of a given number of pixels from 2 x 2 to 1024 x 1024. In Figure 10a, a 2 x 2 cell configuration with no overlap is shown. It can be seen that the undeformed image has a grey scale pattern within the $2 \mathrm{x}$ 2 cell before deformation. After deformation the grey scale pattern is retained, except its spatial position has moved. By recognition of the grey scale pattern from the undeformed to the deformed condition, the deformation of the specimen can be obtained. In three-dimensional analysis an extra initial step is required where the out-of-plane deformation is obtained by calculating the distance of the surface under analysis from a calibration plane (usually in the form of plate with a known and regular geometric pattern inscribed on it); this defines the 'working volume' and the position of the two cameras relative to each other. Once this procedure has been completed, three-dimensional displacement information is obtained from which the in-plane strains are derived. The choice of cell size selection is a compromise between strain and spatial resolution; the larger the cell size, the more data there is to average over. A second factor to be considered in the compromise is cell overlap, as shown in Figure 10b. The strain is calculated from the deformation vectors in each cell, or in the case of overlapping data each sub-cell. This is indicated by the gauge length shown in Figure 10a and Figure 10b; the overlap shortens the gauge length. Therefore the increase in spatial resolution shortens the distance over which the strain is measured. This inevitably will create more scatter as the measurement region decreases.

Firstly, the optimum combination of cell size and overlap was investigated by loading M1 specimens in uniaxial tension. The surface pattern was the recommended fine paint speckle surface pattern. The specimen was strained by approximately $0.1 \%$ in an Instron 5569 servo mechanical test machine and the strain recorded by the long gauge extensometer (gauge length $50 \mathrm{~mm}$ ) attached to one side of the specimen with DIC data being collected from the other. The DIC recorded an image before deformation and a second at the end of the test. The two images were correlated using 10 combinations of processing parameter; the cell size was 128 or 64 pixels (equivalent to approximately 5 or $2.5 \mathrm{~mm}$ ), while the cell overlap was set to $0 \%, 25 \%, 50 \%, 75 \%$ or $87 \%$. (It is important to note that the algorithm used for the correlation can only cope with interrogation cell sizes in powers of two.) The test was run three times to check repeatability of DIC strain values. Figure 11 plots the strain from the DIC obtained in the longitudinal direction for each processing combination normalised against the extensometer value and it can be seen that there is a variation between both the parameter combinations and the tests. It is expected that under simple tension the strain would be uniform across the specimens. However, large variations were observed in the full-field strain plots particularly when using larger cell overlaps. To obtain a measure of the variation, centreline plots were taken through the full-field data and a value of coefficient of variation (COV) in each plot was calculated. 
Figure 12 plots the value of the $\mathrm{COV}$ for each processing parameter for test 1 ; the same trend was produced from all three tests. The COV increases markedly with cell overlap, and there is also a step change when the cell size decreased from 128 to 64 pixels. Therefore it was decided that a good compromise between strain and spatial resolution was a cell size of 64 pixels and an overlap of 25\%. It is clear from Figure 11 and Figure 12 that the DIC technique can adequately measure the strain field in the composite material under the tensile test. It is also important to note that by taking average values through many cells in a uniform strain field the strain resolution can be improved from that quoted by the manufacturer.

The next step was to apply DIC to the generic panels loaded in the test rig. DIC was used to monitor the in-plane strain on part of the generic panel during a full scale test. A generic panel manufactured from material M1 was loaded up to a static load of $13.8 \mathrm{kPa}$ (2 psi) in 10 equally spaced steps. The DIC cameras were setup on a large, rigid stand on a mounting beam approximately $400 \mathrm{~mm}$ apart such that the cameras are pointing vertically down to the generic panel (Figure 13). The cameras were approximately $430 \mathrm{~mm}$ from the surface of the generic panel each at approximately $20^{\circ}$ to the area of focus. For the purposes of a proof of concept, the DIC is focused on one small part of the generic panel (Figure 13). The DIC focused on a region $80 \mathrm{~mm} \times 70 \mathrm{~mm}$ at the front left corner of the core, which from the FE result was known to be a region of high strain. An initial, reference, pair of images was taken whilst the generic panel was unloaded, and then at each load step another pair of images was taken. The in-plane strains were calculated by correlating between the first and the last images to measure the strains developed by a static load of $13.8 \mathrm{kPa}$. Initially, the strains were processed using a cell size of $64 \times 64$ and an overlap of $25 \%$ as suggested by the feasibility tests on tensile strips (see above). However, it was not possible to produce a usable strain map with this procedure. Instead, a multi-pass approach was used with an initial a cell size of 256 and an overlap of $50 \%$, followed by a cell size of 128 with an overlap of $25 \%$ only, so spatial resolution is compromised. The difference in the test set-ups is the reason the same data processing procedure cannot be adopted. The tensile test provides a constant strain across the surface of the specimen, and therefore it is possible to measure an average over the whole specimen. However, there is a large variation in strain across the surface of the panel and therefore local accuracy is more important.

Figure 14 shows a full-field plot of the in-plane strain in the longitudinal direction of the generic panel from both DIC and that expected from the FE model. The black lines on the images indicate the same areas on each plot. Figure 14a plots the raw strain data from DIC and demonstrates that to achieve accurate strain measurements a coarse spatial map must be accepted. The strains from the individual nodes in the FE model were plotted on to a regular grid with the same resolution as the DIC plot and are shown in Figure 14b. Figure 14c and d show smoothed images of both the DIC and FE data, where the raw image has been interpolated over a finer grid using Matlab. The smoothed plots aid the 
interpretation of the very noisy raw data. It is clear that both smoothed plots show strains across the surface from a minimum of around $0 \%$ strain to a maximum of $0.15 \%$ strain and both show a trend of increasing strain from the bottom right region to the top left. The strain along the black lines is plotted in Figure 15 for both the DIC and FE. The DIC records a maximum strain of $0.151 \%$ whilst the FE shows a maximum of $0.144 \%$, and both lines have a reasonable fit.

This work clearly demonstrates that quantitative full-field data can be obtained from the generic panels using DIC and that the test rig is meeting the objective of compatibility with optical strain measurement techniques. However, to obtain the necessary strain accuracy and resolution the DIC was only applied to a small region of the whole panel (approximately $80 \mathrm{~mm}$ by $60 \mathrm{~mm}$ ) and during the feasibility test a number of challenges have been discovered for its use to provide full-field data of the larger structure. With a field of view of only $80 \mathrm{~mm}$ by $60 \mathrm{~mm}$ a minimum of 60 images will be required to measure the strain in the whole panel. Capturing and processing this large number of images would prove an onerous task and would be very time consuming. This would be exacerbated by the need to calibrate the system for every image as a calibration must be performed whenever the cameras are moved. With 60 image sets and 60 calibrations, full-field analysis of the generic panel could take in excess of 15 hours.

\subsection{Thermoelastic stress analysis (TSA):}

Thermoelastic Stress Analysis (TSA) is a well-established, non-contacting technique for the evaluation of stresses in engineering components, e.g. [17]. The technique is based on the use of an infra-red detector to measure the small temperature change associated with the thermoelastic effect. In the current work the Silver $480 \mathrm{M}$ system manufactured by Cedip Infrared Systems is used to collect the TSA data. This system is radiometrically calibrated so it is possible to directly obtain the thermoelastic temperature change and correct for any changes in the specimen surface that occur during testing [18]. The output from the detector provides the thermoelastic temperature change, $\Delta T$, which is related to the change the stresses. For an orthotropic material, such as laminated composites $\Delta T$ can be related to the stresses in the materialas follows [19]:

$$
\Delta T=-\frac{T}{\rho C_{p}}\left(\alpha_{L} \sigma_{L}+\alpha_{T} \sigma_{T}\right)
$$

where $\alpha_{L}$ and $\alpha_{T}$, are the coefficients of linear thermal expansion in the longitudinal and transverse material directions, $\sigma_{L}$ and $\sigma_{T}$ are the stresses in these material directions, $T$ is the surface temperature of the component under investigation, $\rho$ is the density and $\mathrm{C}_{p}$ is the specific heat at constant pressure. 
It is possible to combine the materials constants in this equation, i.e. $\alpha_{L}, \alpha_{T}, \rho$ and $\mathrm{C}_{p}$ into two calibration constants $K_{L}$ and $K_{T}$ as follows:

$$
\Delta T=T\left(K_{L} \sigma_{L}+K_{T} \sigma_{T}\right)
$$

where $K_{L}=\frac{\alpha_{L}}{\rho C_{p}}$ and $K_{T}=\frac{\alpha_{T}}{\rho C_{p}}$.

To obtain stress values the thermoelastic constants, $K_{L}$ and $K_{T}$, are required. The simple unidirectional stress state in specimens loaded under uniaxial tension provides the ideal method to measure the thermoelastic constants. Therefore strips of the face sheet material were produced so that one could be loaded in the test machine in the x-direction and in the y-directions shown in Figure 2. This means the tensile strips had the surface ply orientated at $0^{\circ}$ to the test machine axis to obtain $K_{L}$ and at $90^{\circ}$ to obtain $K_{T}$.

Equation (1) was developed assuming adiabatic conditions; in practice pseudo adiabatic conditions are achieved by cyclic loading. In this respect loading frequencies of around $10 \mathrm{~Hz}$ are recommended [10]. It would be impossible to load at this rate using the test rig. Therefore it was decided to use the 1 Hz loading frequency for the TSA work in the rig. As epoxy has a low thermal conductivity this was considered practical and the applied pressure range of $10 \mathrm{kPa}$ (1.5 psi) could be achieved at this frequency.

Thermoelastic constants were measured from tensile strips manufactured from both materials M1 and M2 subjected to a mean load of $3.5 \mathrm{kN} \pm 3 \mathrm{kN}$, i.e. a load range of $6 \mathrm{kN}$. To provide the 'calibration constants' for the full scale tests the tensile strips were cycled at $1 \mathrm{~Hz}$, and to provide a comparison with the actual thermoelastic constant the strips were also cycled at $10 \mathrm{~Hz}$. Figure 16 shows the TSA images of both materials M1 and M2 with surface plies at $0^{\circ}$ and $90^{\circ}$ at loading frequencies of 1 and $10 \mathrm{~Hz}$. The response from both material types is similar; therefore it is clear that both materials are responding in a similar manner when subjected to the same load. It is important to note the difference in response between the longitudinal specimens and the transverse specimens. The longitudinal specimens show an average change in temperature of between 0.03 and $0.05{ }^{\circ} \mathrm{C}$ and the transverse specimens show a change of temperature between 0.12 and $0.14{ }^{\circ} \mathrm{C}$. It is also of interest that in the TSA images from M2 the loose stitches, which hold the non-crimp fibres together before infiltration, can be discerned. It is considered that the stitches are visible because they are produced from a different material than the rest of the specimen and/or resin accumulates around them and provides a different response. By considering the face sheet material as a homogeneous block, under tensile loading only the longitudinal stress is present, and therefore the transverse stress term in Equation (2) is zero. By calculating the applied stress from the applied load range and the cross- 
sectional area of the specimens it was possible to calculate $K_{L}$ and $K_{T}$. The average of the change in temperature from each specimen was used to calculate the thermoelastic constants shown in Table 2. On average, the thermoelastic 'constants' change by between 30 and $40 \%$ when the loading frequency is changed from 1 to $10 \mathrm{~Hz}$. The longitudinal response decreases when the loading frequency is increased, and the transverse response increases. This is a clear indicator that the response of the material at $1 \mathrm{~Hz}$ is not adiabatic and that there is influence from the stress induced temperature change from the subsurface plies. It is important to note at this stage, as the in-plane stress field is uniform, the non-adiabatic response can only be as a result of through thickness heat transfer because of the different stress induced temperature change in each ply. The FE models showed that the transverse stress in the panels was practically uniform and much smaller than the longitudinal stress, i.e. similar to the tensile strips. Therefore, the thermoelastic constant derived at 1 $\mathrm{Hz}$ was used to calibrate the response from the panels.

The cyclic tests described in Figure 9 confirmed that the test rig was capable of producing the type of consistent cycle necessary to perform TSA. The next step was to conduct a full-scale test on the generic panels manufactured from both the M1 and M2 techniques to demonstrate the use of TSA and show that this approach can be used to discern differences in the stress distributions in the panels. The panels were taken to a mean load of $10 \mathrm{kPa}$ (1.5 psi), and then loaded in displacement control with $3 \mathrm{~mm}$ amplitude. This imparts a range of load of approximately $10 \mathrm{kPa}$ (1.5 psi) to the panel. Due to the restraint of the movement of the rig, the loading was cycled at $1 \mathrm{~Hz}$. To provide adequate resolution of the stresses within the panel using TSA it is necessary to take 32 separate images that can be 'stitched' together in post-processing. The image at the top of Figure 17 shows the combined result of the 32 TSA images of the generic panel produced from M1 and the image at the top of Figure 18 shows the response from the generic panel produced from M2. From the raw TSA data it is possible to see areas of stress that are much larger than the background. In Figure 17 the areas of high stress have been identified as the corners of the honeycomb and along the line of bolt attachments.

The TSA data was compared to the stress field of the FE model of the generic panel. To allow a direct comparison, the TSA and FE data must be converted into the following form by rearranging Equation 2:

$$
\frac{\Delta T}{T K_{L}}=\Delta \sigma_{L}+\frac{K_{T}}{K_{L}} \Delta \sigma_{T}
$$

TSA

FE

The TSA data is calibrated using $K_{L}$, and it is necessary to multiply $\sigma_{T}$ from the FE data by $K_{T} / K_{L}$ to match the data. For the purposes of comparison, the FE model discussed in section 2 was altered to 
accommodate the material properties, thickness and lay-up of M2. To match the model to the calibration approach, the face sheets were treated as homogeneous orthotropic blocks, although it was possible to obtain a ply-by-ply stresses with the model. The FE and TSA show close correlation (Figure 17 and Figure 18), both in position and value of the stresses, both background and stress concentrations. This is confirmed by taking a line plot through the stress concentration on the corner of the core, shown by the lines in Figure 17 and Figure 18 (see Figure 19). The correlation between TSA and FE is confirmed by Figure 19, in particular for generic panel M1. The TSA result from the panel produced using M2 shows more noise than the plot from M1 due to the stitches that were visible during the tensile strip tests in Figure 16. The results are promising and demonstrate the use of TSA as a full-field method to analyse the stress state in the generic panels. It is interesting that the TSA data from the M1 panel has a much larger stress concentration than that of the M2 panel. Further work is required to determine if this is a real feature or an artefact of non-adiabatic behaviour. However, it is evident that the non-crimp fabric (M2) is distributing the stress differently and that this is not being predicted by the FE.

Most practitioners of TSA will be surprised to see that a response that is non-adiabatic producing such consistent results. This warrants some explanation. As the FE model has been validated using both point measurements and the DIC, it is reasonable to assume the data generated for the TSA comparison is correct. So, in a sense, the FEA is validating that the non-adiabatic response from the panels at $1 \mathrm{~Hz}$ loading frequency and the good correspondence is demonstrating that the TSA is producing meaningful results. The reason for this is that in the panels the transverse stress field is practically constant and small in comparison to the longitudinal stress field. However, the longitudinal stress field has a significant gradient, which does not appear to introduce significant non-adiabatic behaviour. Therefore, it may be assumed that the in-plane heat transfer due to the non-adiabatic conditions is much smaller than the through-thickness heat transfer allowing the TSA calibration to be applied effectively. This clearly warrants further detailed investigation and will be the object of future work.

\section{Conclusions}

It has been shown that a full scale test rig can be designed to accurately impart representative pressure loads to obtain the mechanical performance from composite panels using optical strain measurement techniques. The rig is based on the use of a standard servo-hydraulic test machine that loads the test panels via a fully constrained water filled cushion. The pressure within the cushion is completely transferred to the surface of the test panel. Preliminary tests have shown the consistency of the application of the pressure, and the panels' measured deformation using a displacement transducer. Secondly the ability of the test rig to maintain sinusoidal cyclic loading at both 1 and $2 \mathrm{~Hz}$ has been 
demonstrated. Finally, both DIC and TSA were applied as full-field techniques to investigate the strain and stress states in the generic panel. It was shown that it is possible to obtain useful results from TSA under non-adiabatic conditions by calibrating the data using specimens subjected to similar non-adiabatic conditions. The results of the TSA were used to validate FE models of the panels. It was demonstrated that the FE could not fully model some of the features of the materials that were picked up in the TSA.

The work in the paper describes the commissioning and validation of the test rig and demonstrates its potential in full-scale assessments of sandwich structure panels. Future work will include application to different material combinations and panel geometries to include features such as cut-outs.

\section{References}

1. National Composites Network, www.ncn-uk.co.uk, 04/2008

2. Chestney, J.A. and Sarhadi, M. A prototype manufacturing cell for automated assembly of fibre reinforced composite preforms. In $4^{\text {th }}$ international conference on Automated Composites. 1995. Notthingham UK Institute of Materials.

3. Crump, D.A., Dulieu-Barton, J.M and Savage, J. The manufacturing procedure for aerospace secondary structure panels. Journal of sandwich structures and materials. 2009, DOI: 10.1177/1099636208104531, p1-28 In press.

4. Kaufmann, M., Zenkert, D. and Mattei, C. Cost optimisation of composite aircraft structures including variable laminate qualities. Composite science and technology, 2008. p2748-2754.

5. McCarthy, M. BOJCAS: Bolted joints in composite aircraft structures. Air and space Europe. 2001. Vol 3: p1-4

6. Hinrichsen, J., Bautista, C. The challenge of reducing both airframe weight and manufacturing cost. Air and space Europe. 2001. Vol 3: p119-121

7. Stockton, D.J., Forster, R. and Messiner, B. Developing time estimating models for advanced composite manufacturing processes. Aircraft engineering and aerospace technology. 1998. Vol 70: $4445-450$

8. Abraham, D. and Mcllhagger, R. Investigations into various methods of liquid injection to achieve mouldings with minimum void contents and full wet out. Composite part A: Applied science and manufacturing. 1998. 28: p 533-539.

9. Dexter, H.B. Development of textile reinforced composites for aircraft structures. In $4^{\text {th }}$ international symposium for textile composites. 1998. Kyoto, Japan.

10. Dulieu-Barton, J.M. and Stanley, P. Development and applications of thermoelastic stress analysis. Journal of strain analysis. 1998. Vol 33, No2: p 93-104

11. Sutton, M.A., Orteu, J. and Hubert, S. Image correlation for shape, motion and deformation measurements. Springer. 2009 
12. Private communication

13. Bruhn, E.F. Analysis and design of flight vehicle structures. S.R. Jacobs and associates, inc, USA. 1973.

14. Jolma, P., Segercrantz, S. and Berggreen, C. Ultimate failure of debond damaged sandwich panels loaded with lateral pressure - An experimental and fracture mechanics study. Journal of sandwich structures and materials. 2007. Vol 9, No 2: p 167-196.

15. Godara, A. and Raabe. Influence of fiber orientation on global mechanical behaviour and mesoscale strain localization in a short glass-fiber-reinforced epoxy polymer composite during tensile deformation investigated using digital image correlation. 2007, Compos Sci and Technol.

16. Corr, D. and Accardi, M. Digital Image Correlation Analysis of Interfacial Debonding Properties and Fracture Behaviour in Concrete, Eng Fract Mechs, 2007, Vol 74, p109-121.

17. Pagan, N. and Schoeppner, G., Comprehensive composite materials. Edited by A. Kelly and C. Zweben, Perganon, Vol 2, 2000.

18. Dulieu-Barton, J., Emery T., Quinn, S., and Cunningham, P. A temperature correction methodology for quantitative thermoelastic stress analysis and damage assessment. Meas Sci and Technol, Vol 17, pp1627-1637, 2006.

19. Boyd, S. W., Dulieu-Barton, J. M., Thomsen, O. T. and Gheradi, A. Development of finite element model for analysis of pultruded structures using thermoelastic data. Composites Part A: Applied science and manufacturing. Vol 29, p1311-1321, 2008.

\section{List of Figures}

Figure 1: Schematic of wing structure showing secondary structure

Figure 2: Generic panel design

Figure 3: Convergence of maximum displacement with varying element size

Figure 4: FE mesh and contour plot of out-of-plane deformation 
Figure 5: Initial pressure cushion loading concept

Figure 6: Pressure-loading rig concept design

Figure 7: Test rig mounted in the test machine

Figure 8: Static response of the test rig

Figure 9: Cyclic response of test rig

Figure 10: Cell size and cell overlap

Figure 11: Effect of varying the DIC processing parameters in the tensile tests

Figure 12: Coefficient of Variation in the DIC data obtained from the tensile tests

Figure 13: DIC cameras set-up over the generic panel with the region of interest on the generic panel shown on the right

Figure 14: In-plane strain distribution on panel M1 (a) DIC (b) FE, (c) DIC smoothed (d) FE smoothed

Figure 15: Line plots showing strain from (a) FE and (b) DIC along lines shown in Figure 14

Figure 16: TSA images of calibration specimens

Figure 17: TSA data from panel M1 in comparison to the FE model 
Figure 18: TSA data from panel M2 in comparison to the FE model

Figure 19: Line comparison between TSA and FE from plot in Figure 18 
List of Tables:

Table 1: Material properties for FE model of generic panel

Table 2: TSA thermoelastic constants for materials M1 and M2 
Figures

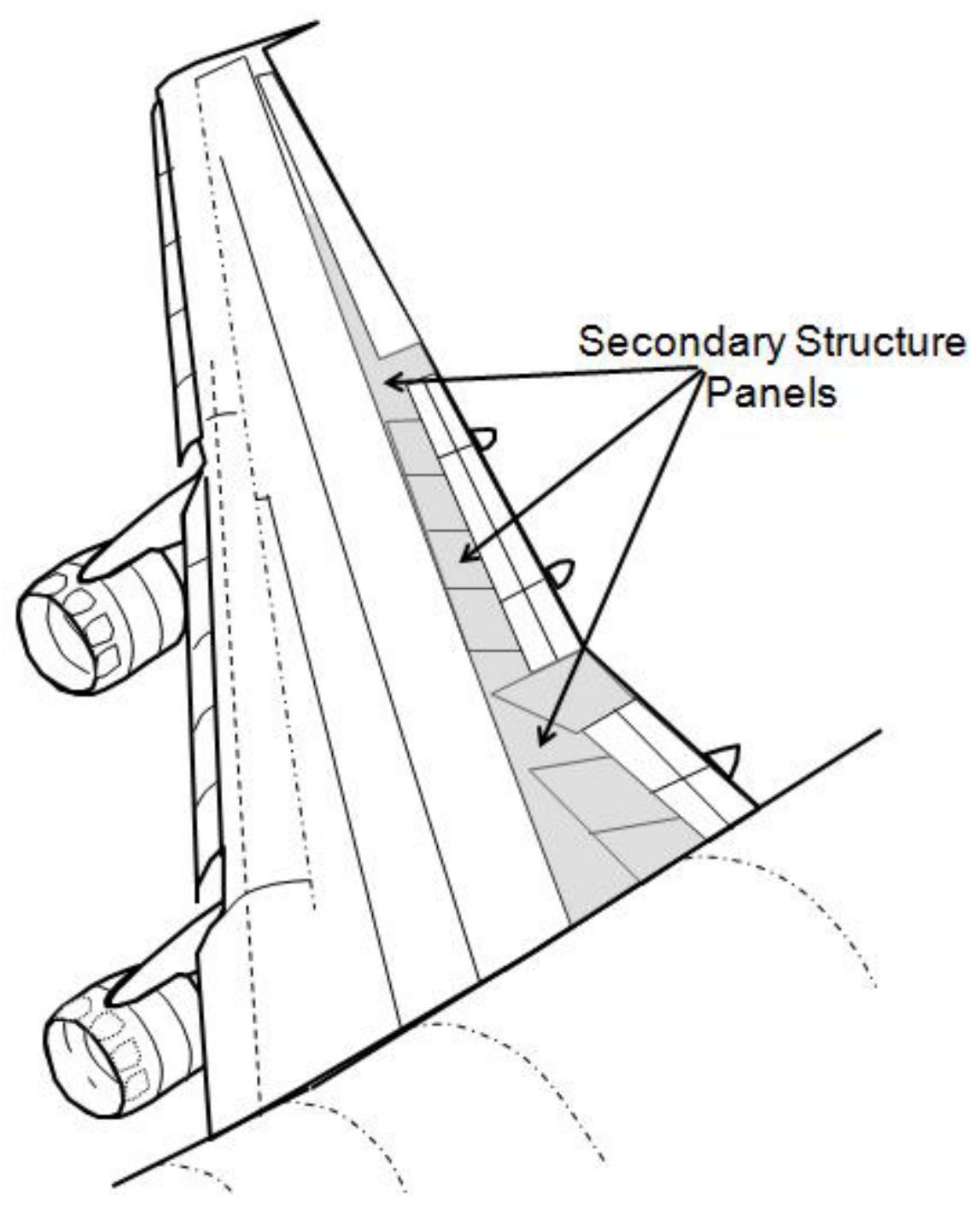

Figure 1: Schematic of wing structure showing secondary structure 


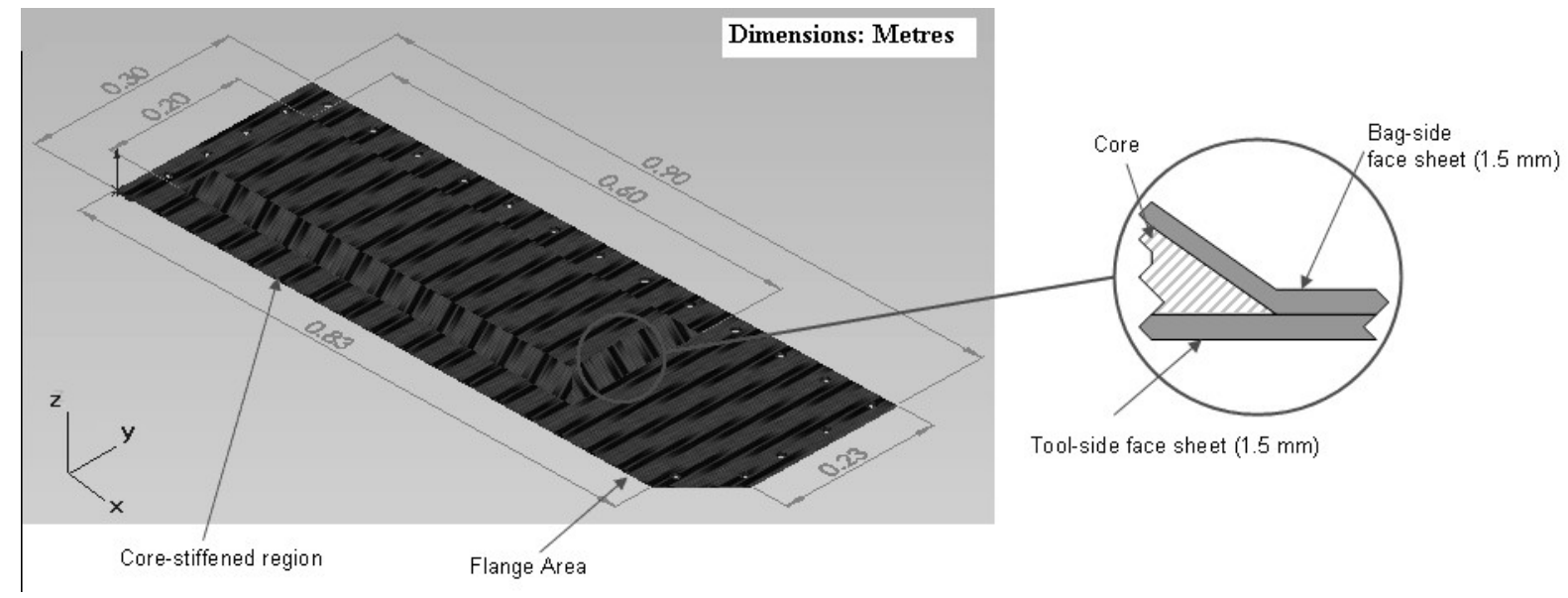

Figure 2: Generic panel design 


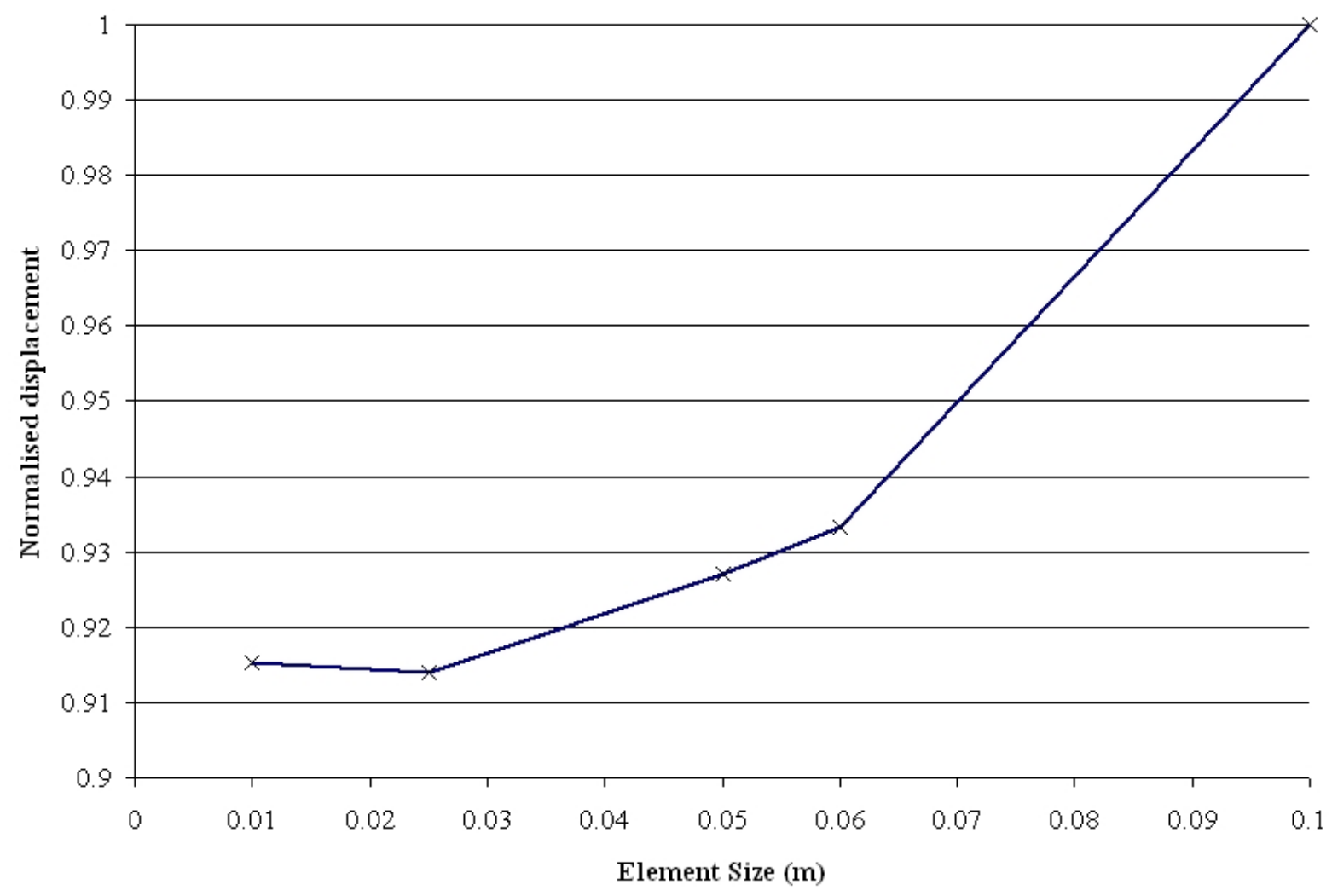

Figure 3: Convergence of maximum displacement with varying element size 

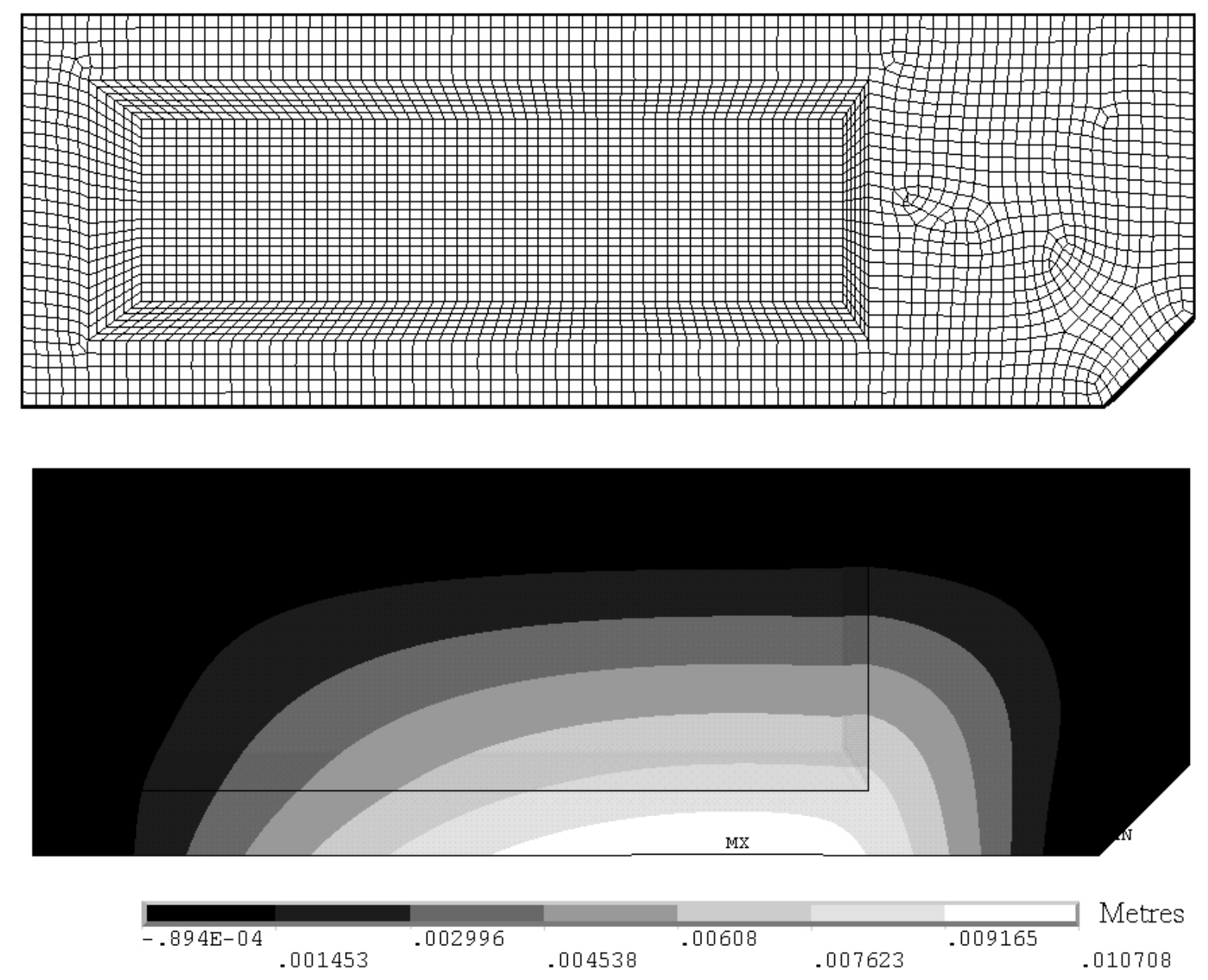

Figure 4: FE mesh and contour plot of out-of-plane deformation 


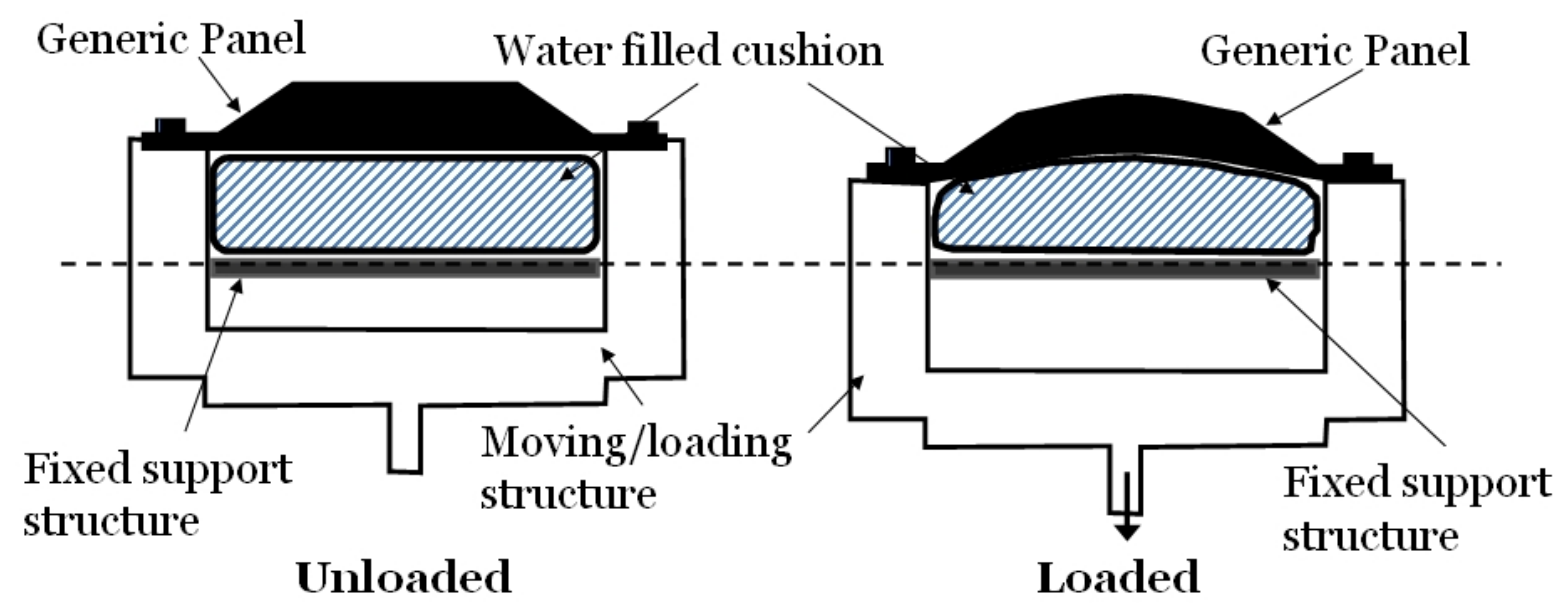

Figure 5: Initial pressure cushion loading concept 


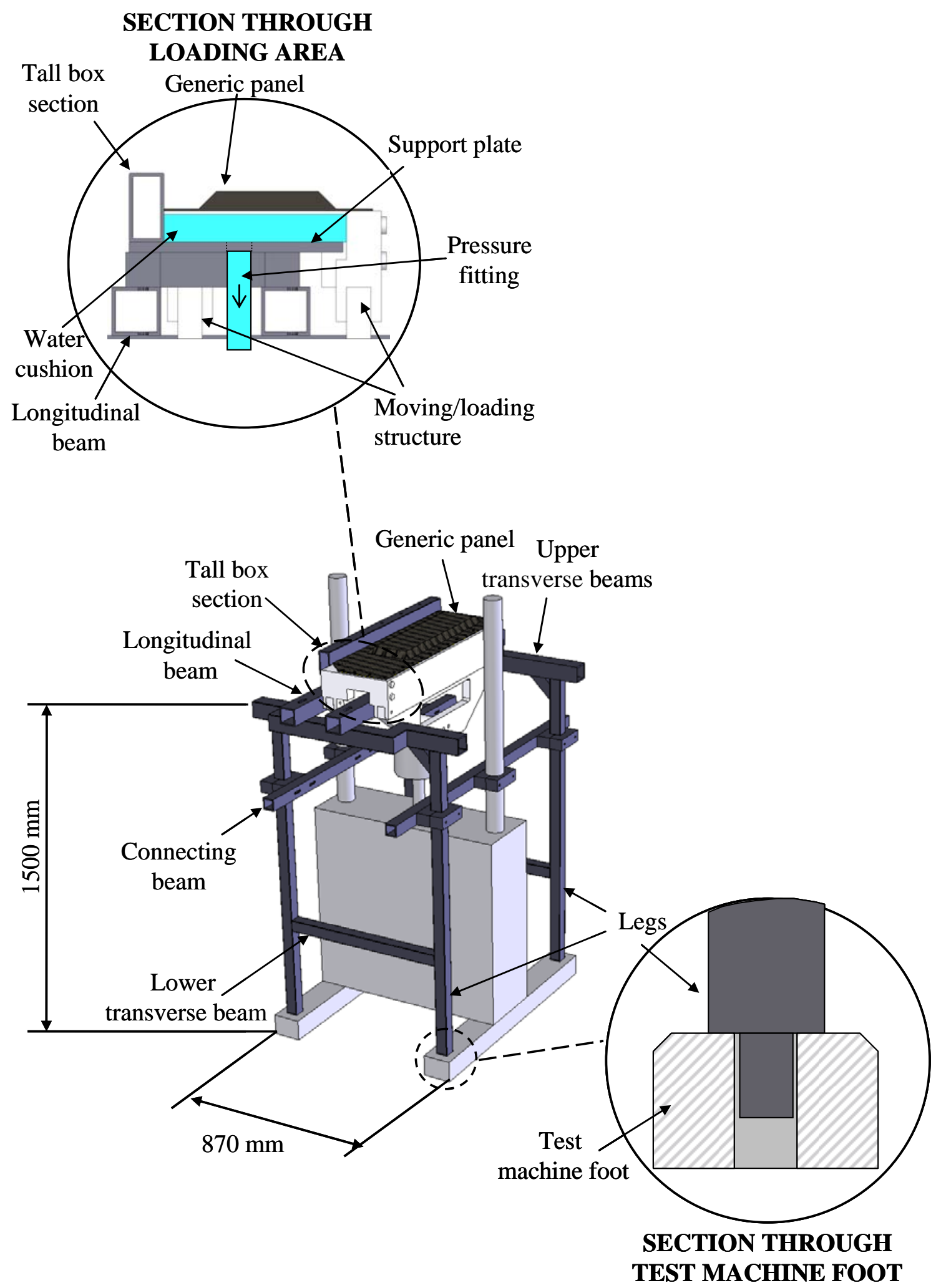

Figure 6: Pressure-loading rig concept design 


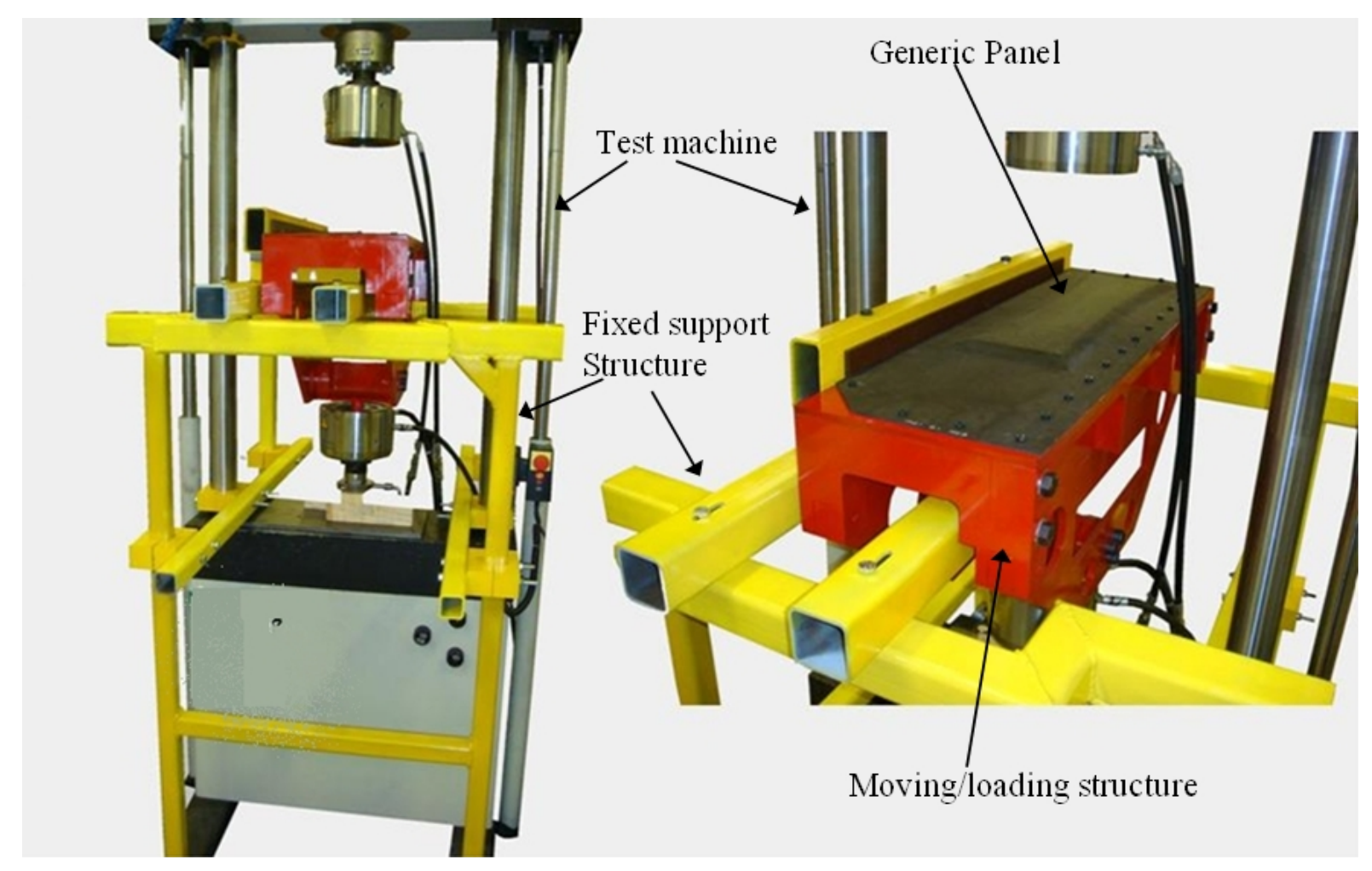

Figure 7: Test rig mounted in the test machine 
(a)

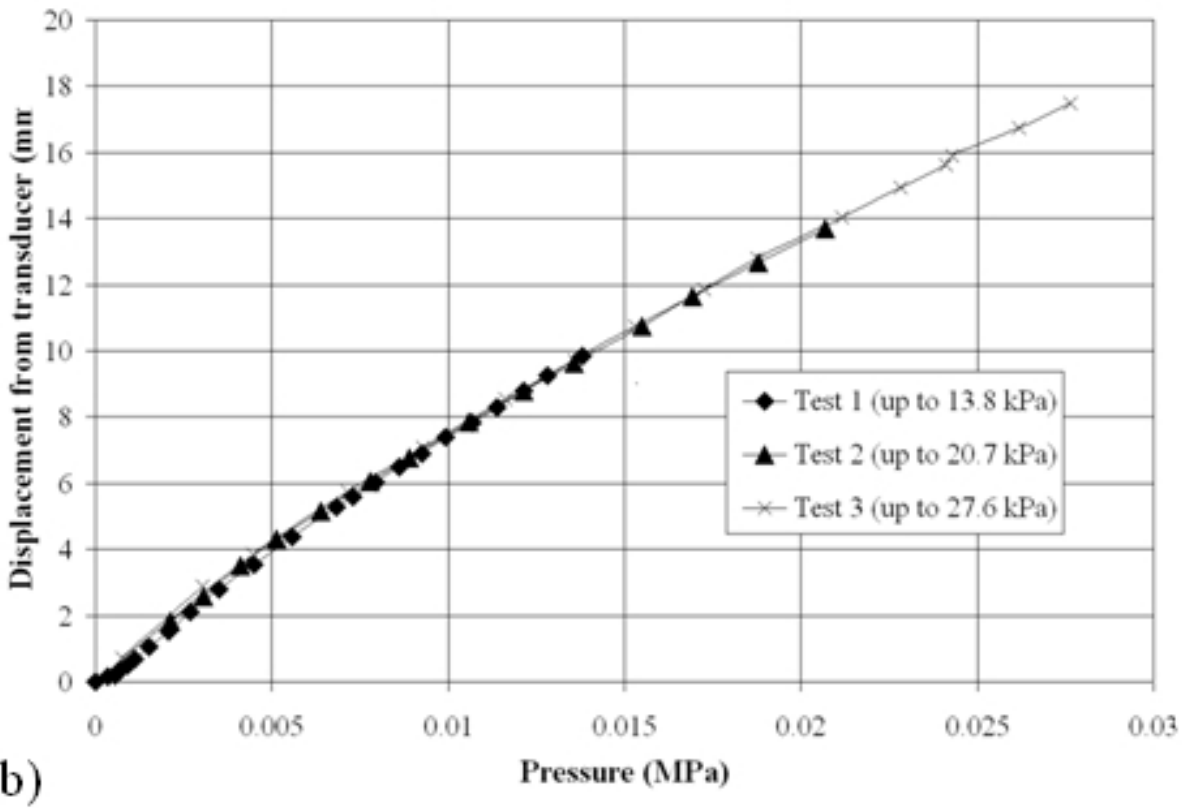

(b)

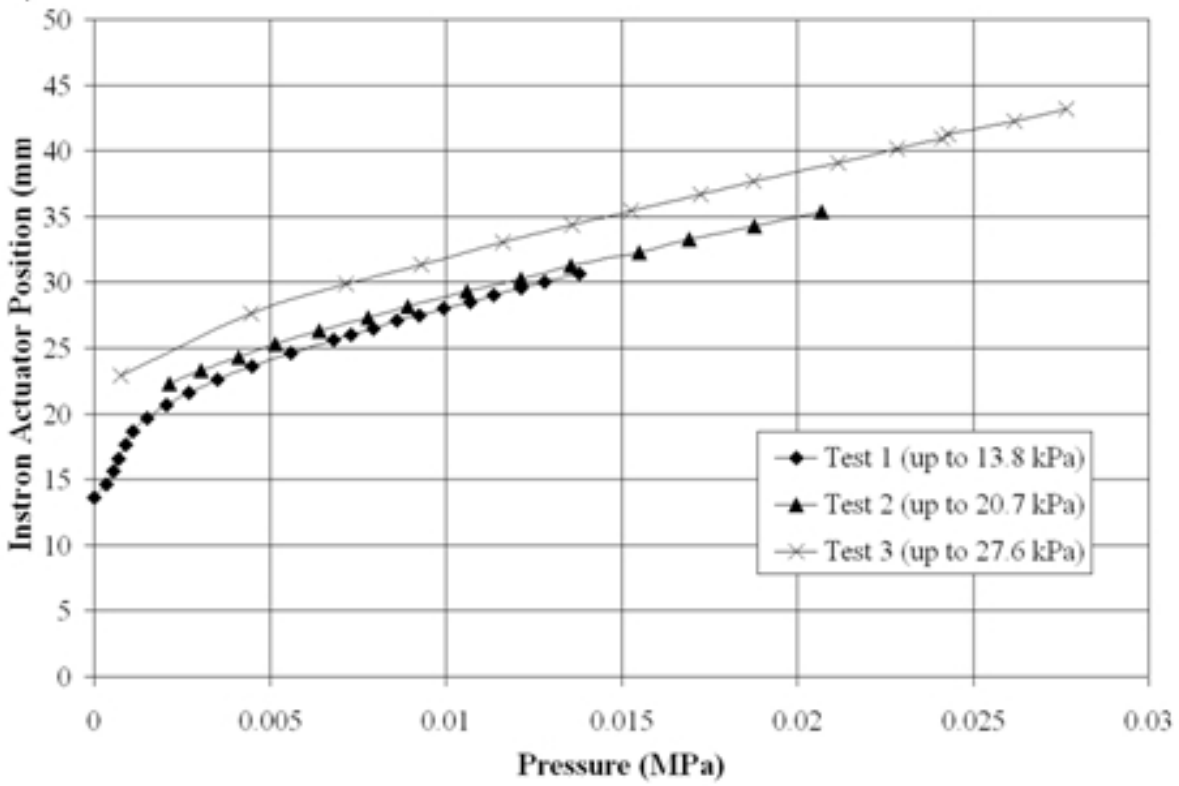

Figure 8: Static response of the test rig 


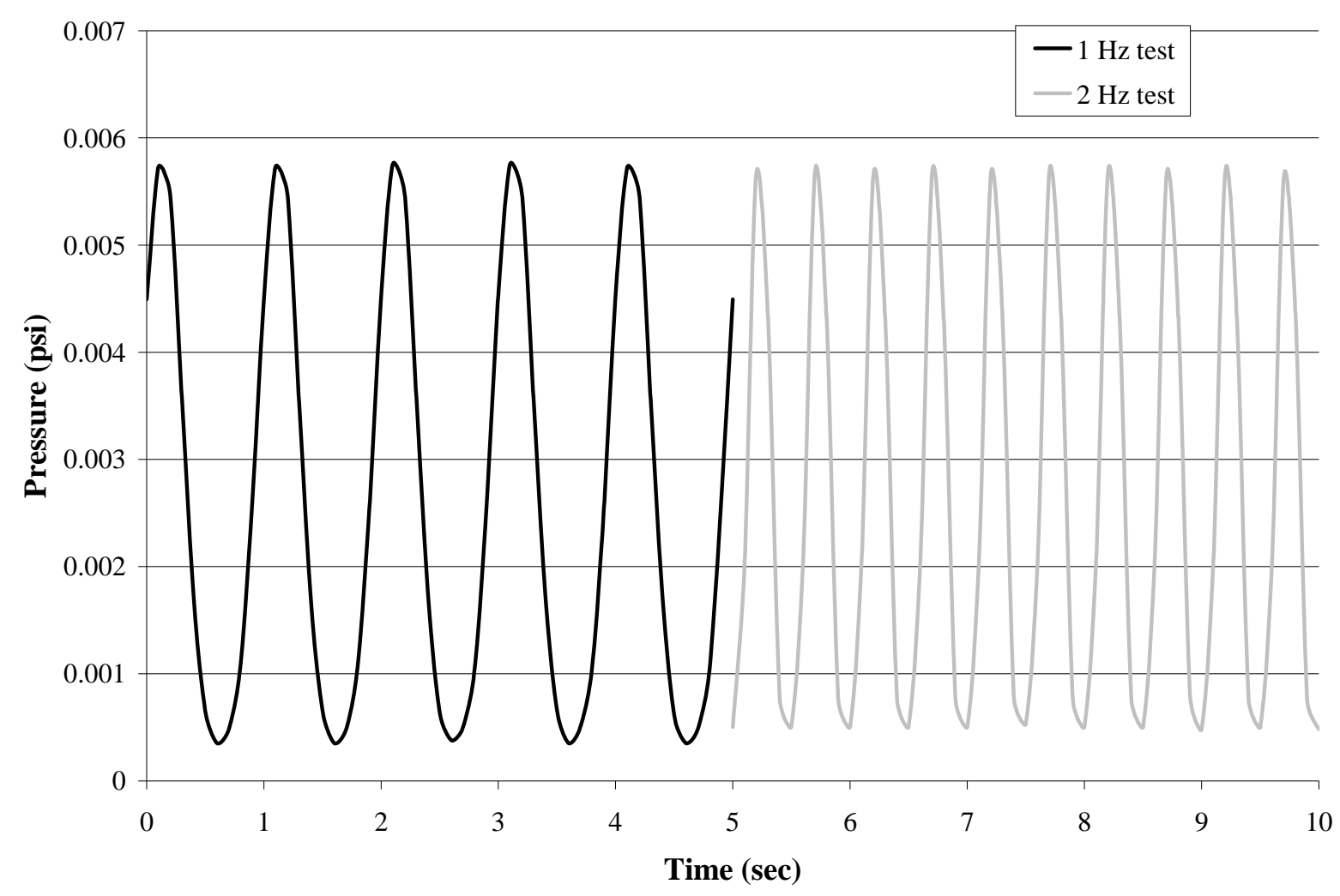

Figure 9: Cyclic response of test rig 
(a)

No overlap

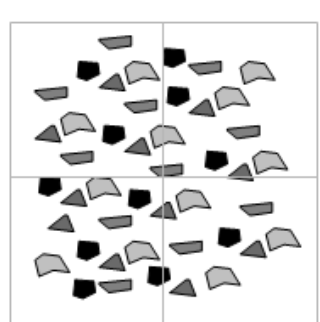

undeformed

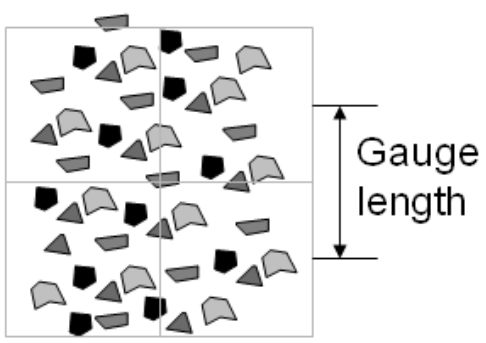

deformed

(b)

$\mathbf{5 0} \%$ overlap

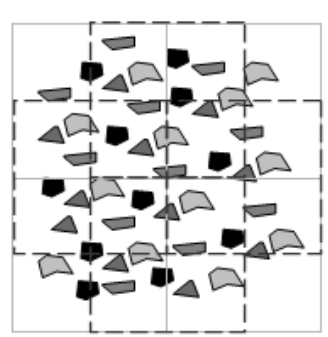

undeformed

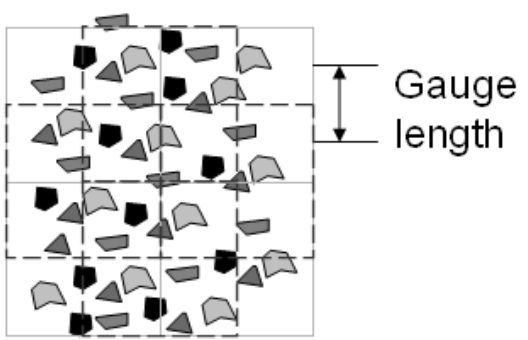

deformed

Figure 10: Cell size and cell overlap 


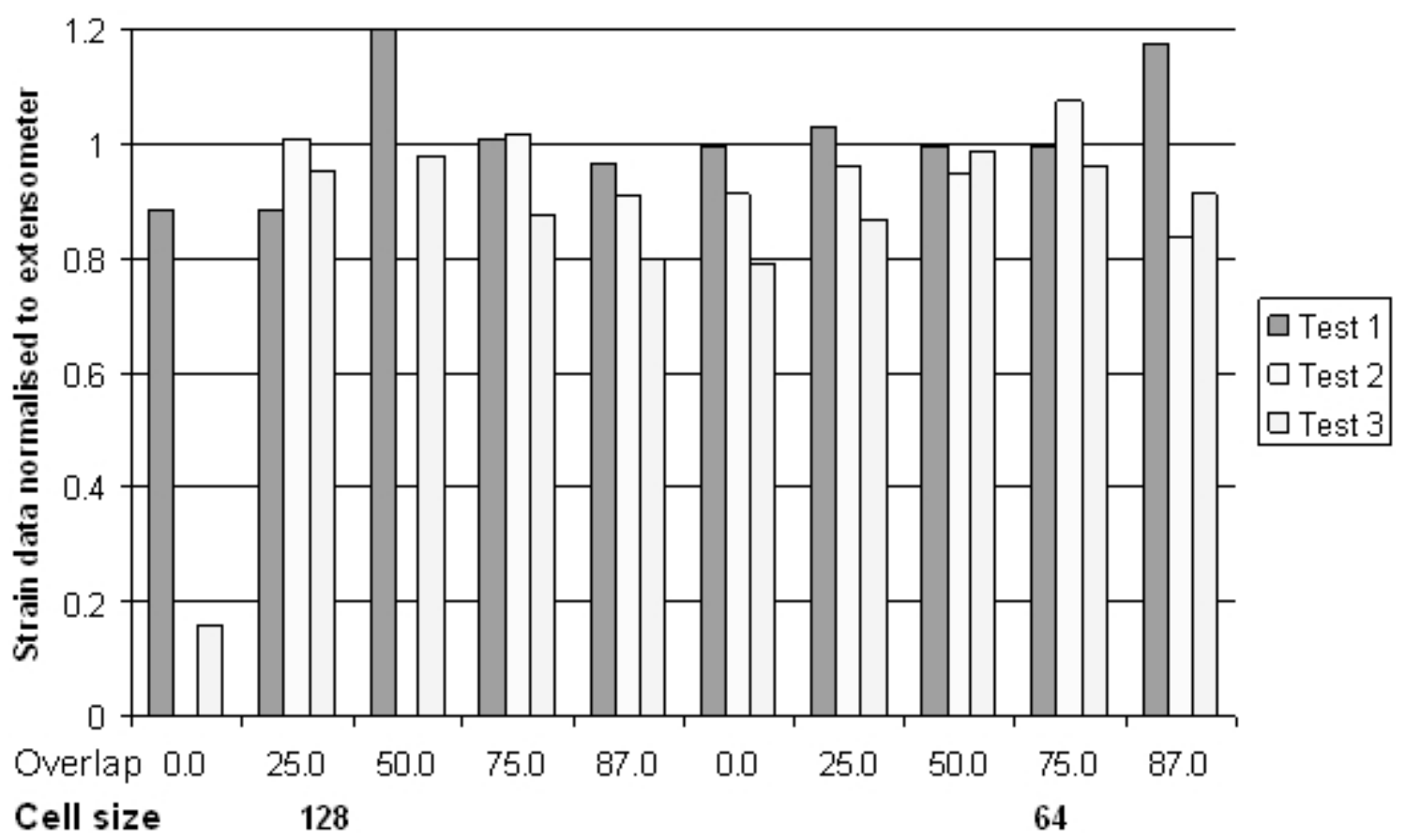

Figure 11: Effect of varying the DIC processing parameters in the tensile tests 


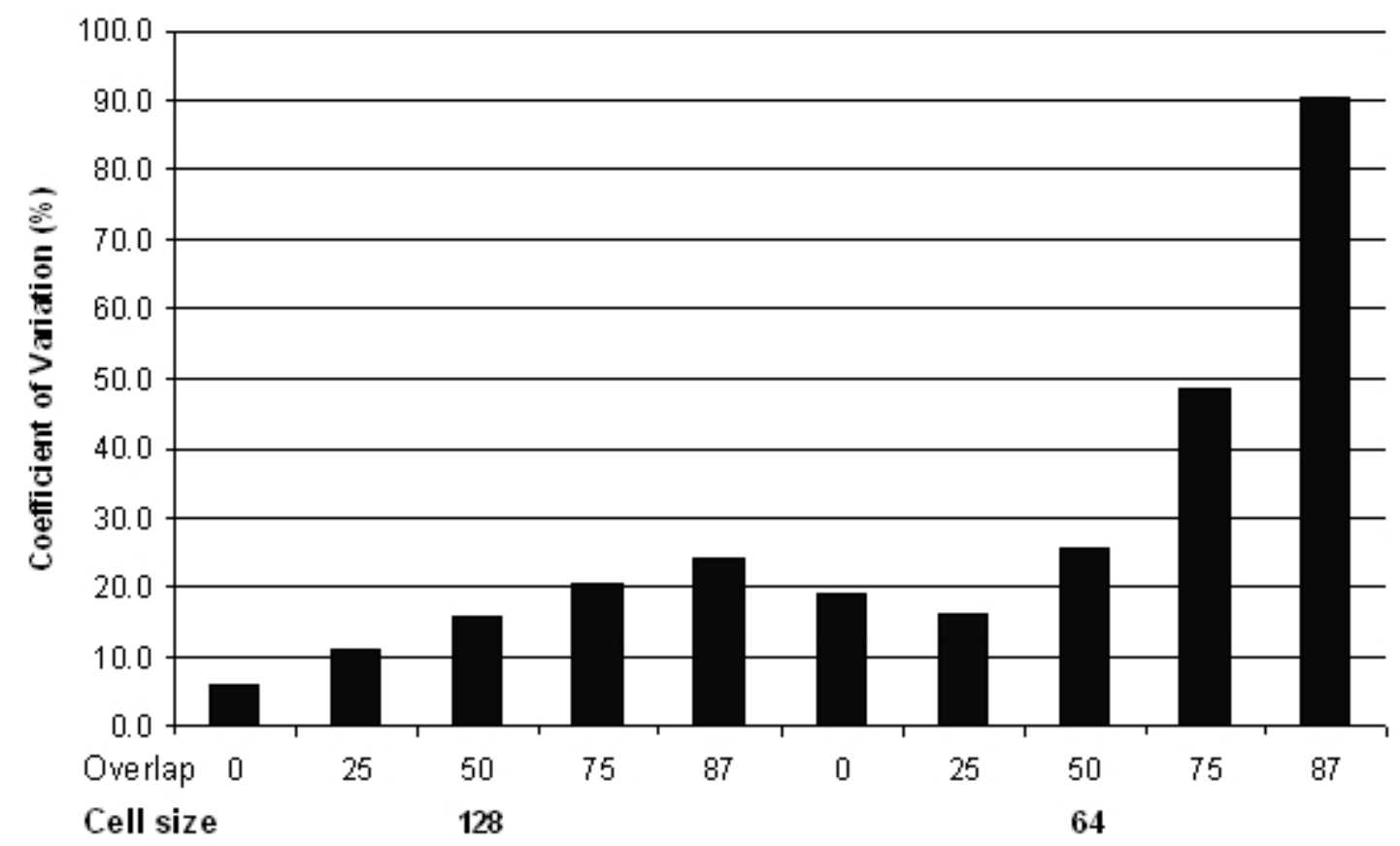

Figure 12: Coefficient of Variation in the DIC data obtained from the tensile tests 


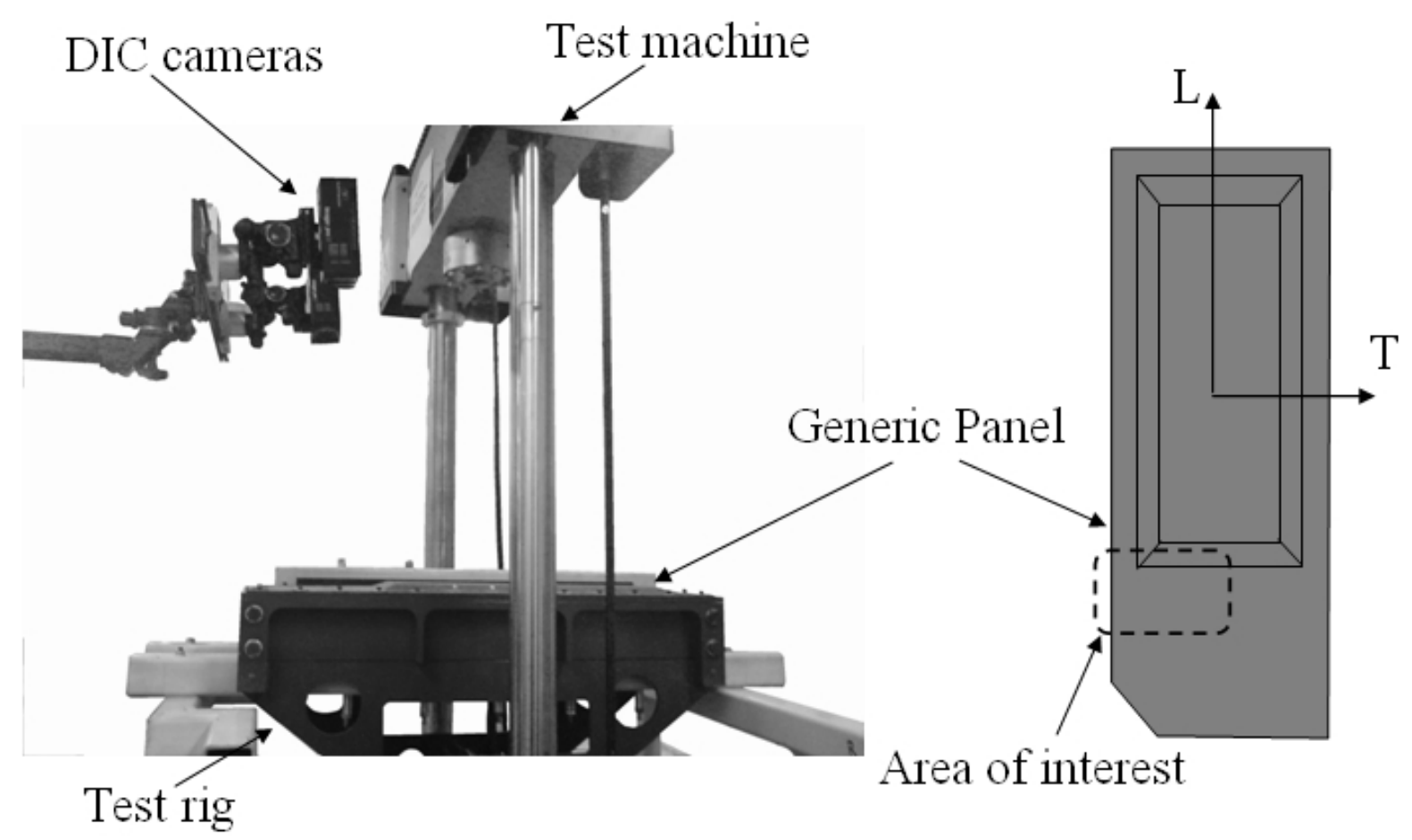

Figure 13: DIC cameras set-up over the generic panel with the region of interest on the generic panel shown on the right 


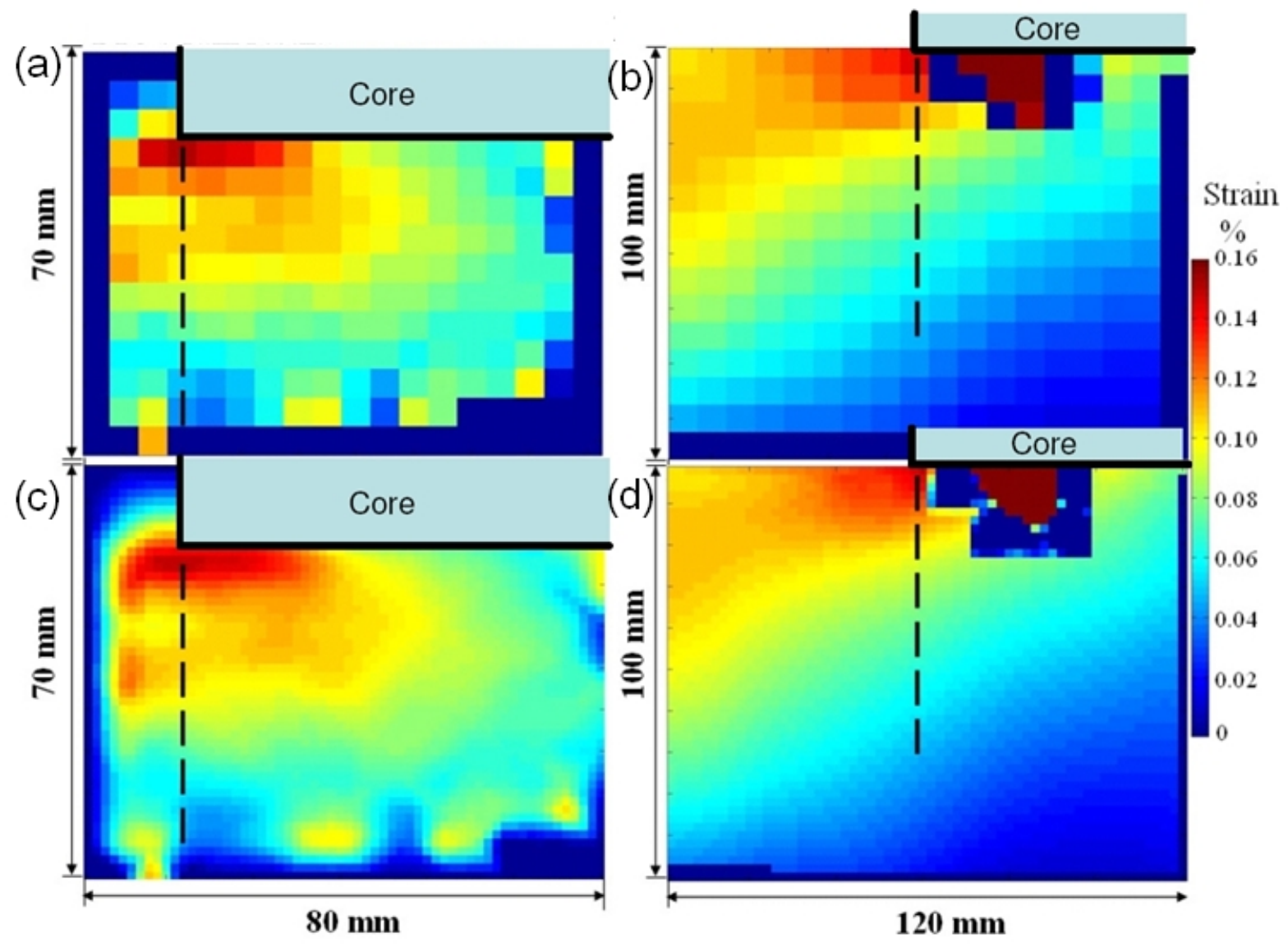

Figure 14: In-plane strain distribution on panel M1 (a) DIC (b) FE, (c) DIC smoothed (d) FE smoothed 


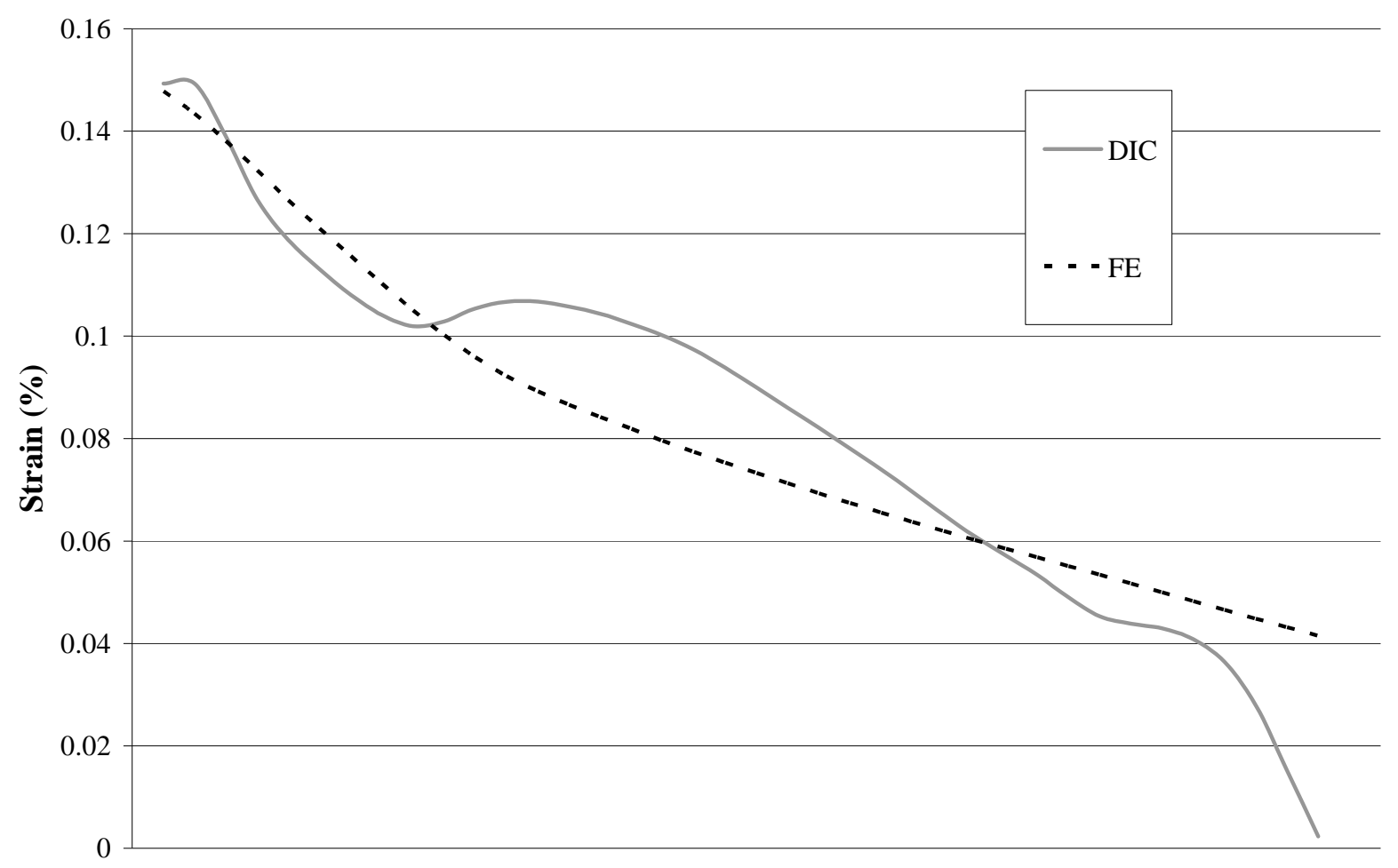

Position

Figure 15: Line plots showing strain from (a) FE and (b) DIC along lines shown in Figure 14 


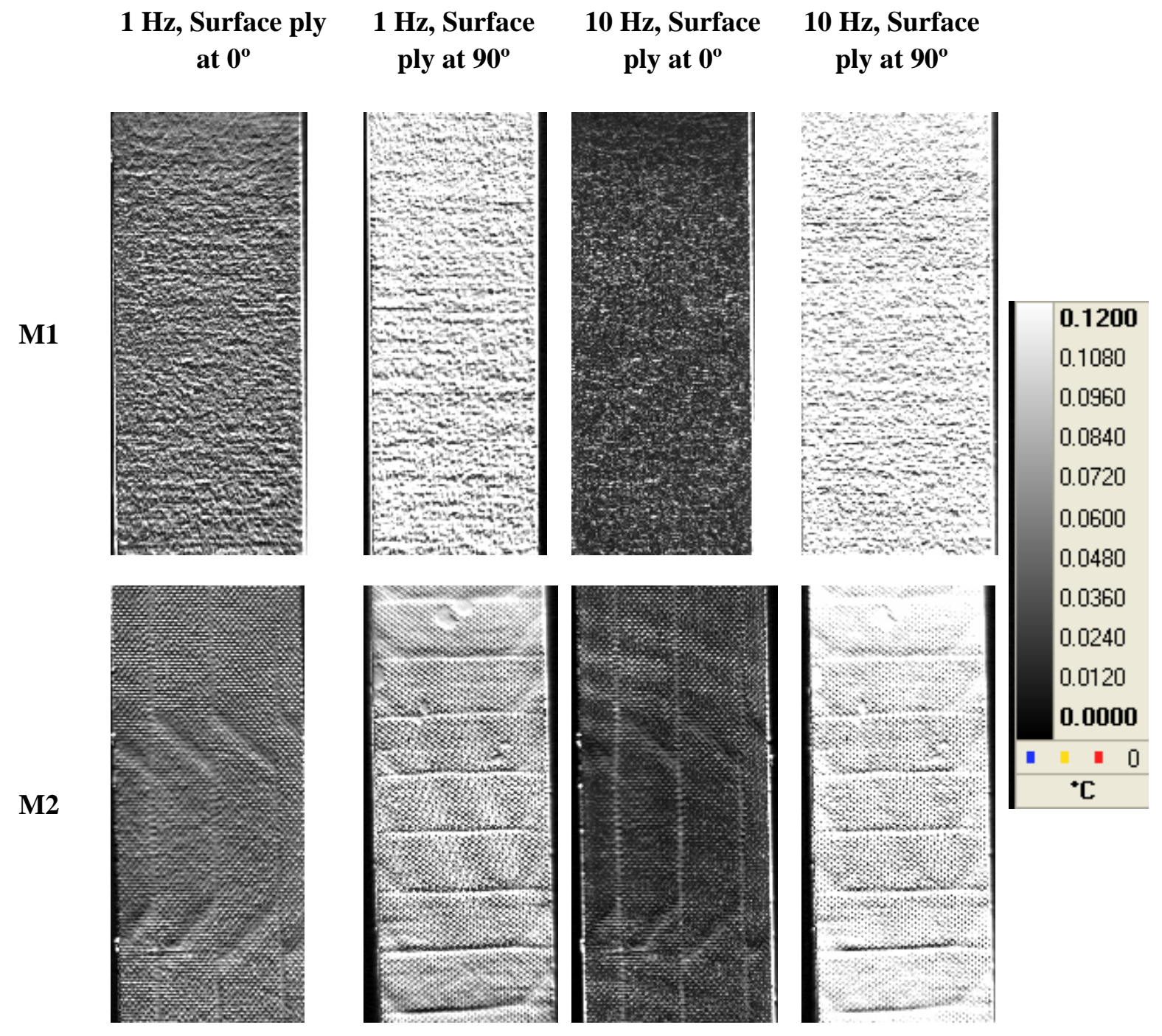

Figure 16: TSA images of calibration specimens 
Experimental Result:

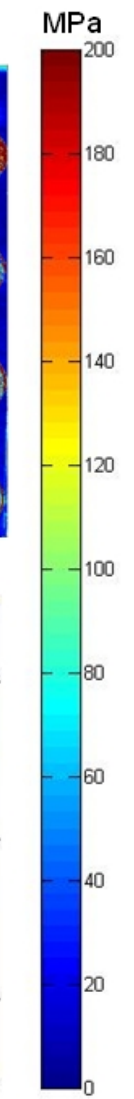

Figure 17: TSA data from panel M1 in comparison to the FE model 


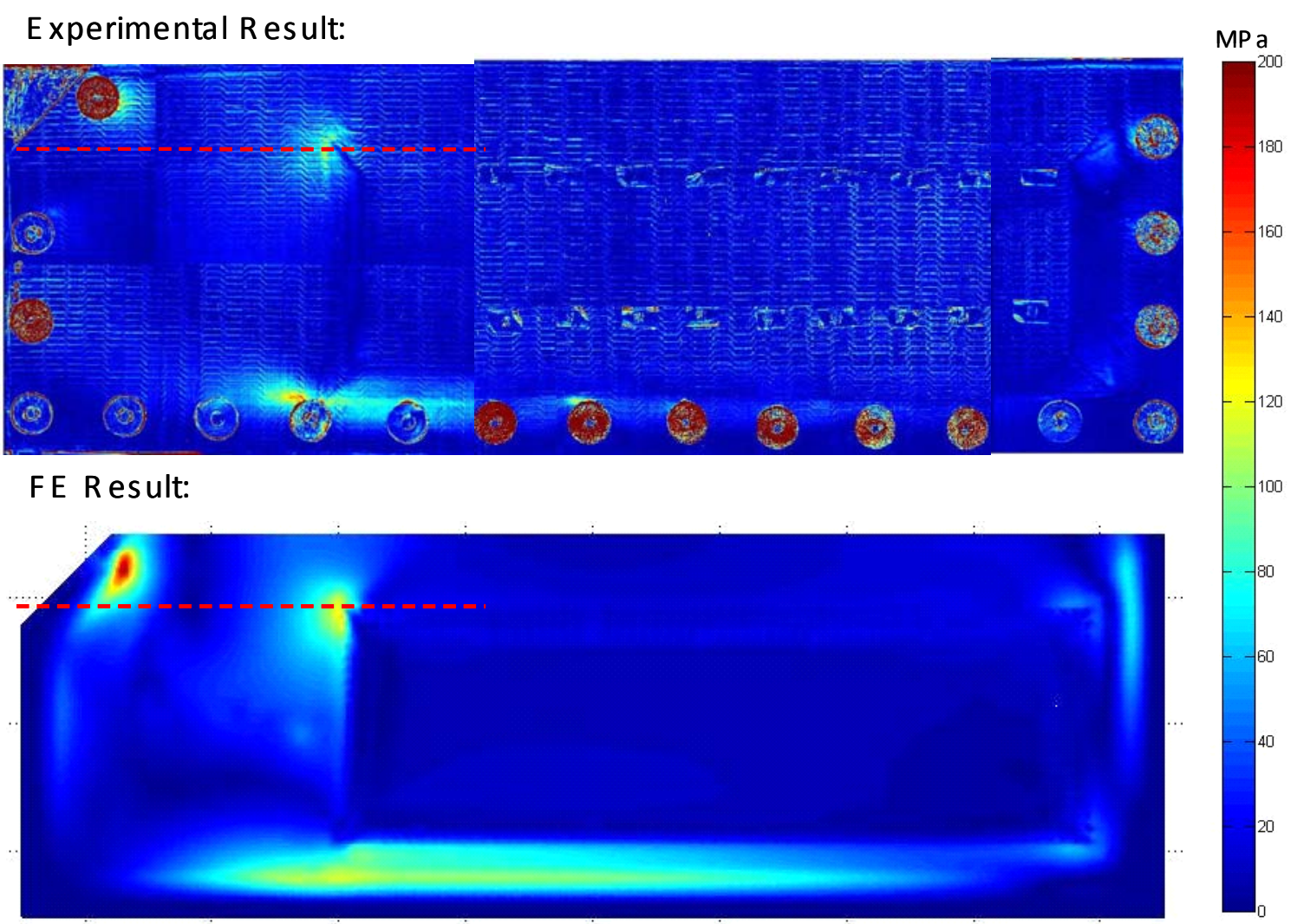

Figure 18: TSA data from panel M2 in comparison to the FE model 


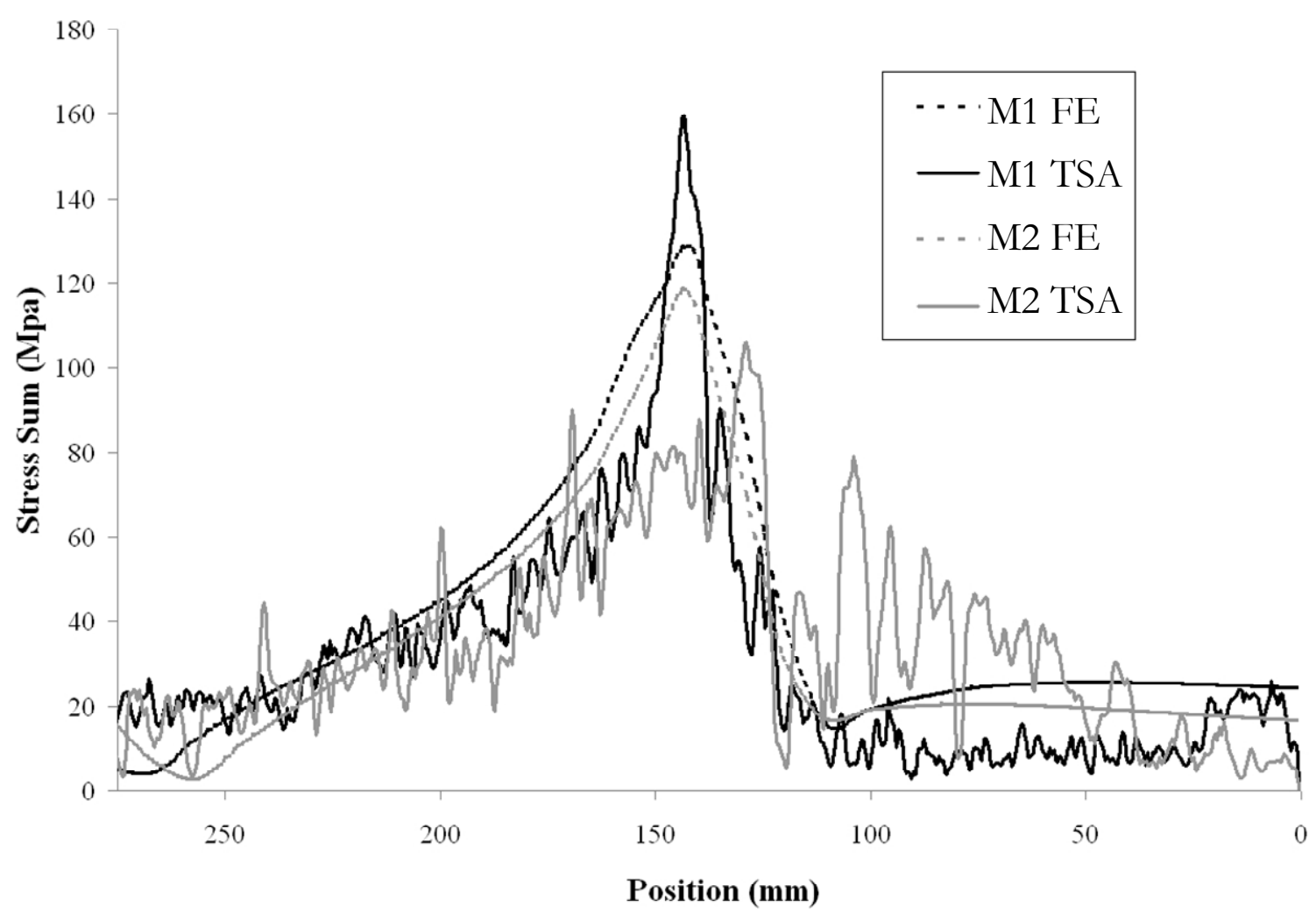




\section{Tables:}

Table 1: Material properties for FE model of generic panel

\begin{tabular}{lcc}
\hline Property & Carbon fibre & Honeycomb \\
\hline \hline $\boldsymbol{E}_{\mathbf{1}}(\mathbf{P a})$ & $134 \times 10^{9}$ & $400 \times 10^{6}$ \\
$\boldsymbol{E}_{2}(\mathbf{P a})$ & $9 \times 10^{9}$ & $400 \times 10^{6}$ \\
$\boldsymbol{E}_{3}(\mathbf{P a})$ & $9 \times 10^{9}$ & $400 \times 10^{6}$ \\
$\boldsymbol{v}_{\mathbf{1 2}}$ & 0.32 & 0.3 \\
$\boldsymbol{v}_{21}$ & 0.09 & 0.3 \\
$\boldsymbol{v}_{23}$ & 0.09 & 0.3 \\
$\boldsymbol{G}_{12}(\mathbf{P a})$ & $6.6 \times 10^{9}$ & $59.3 \times 10^{6}$ \\
$\boldsymbol{G}_{21}(\mathbf{P a})$ & $6.6 \times 10^{9}$ & $32.4 \times 10^{6}$ \\
$\boldsymbol{G}_{23}(\mathbf{P a})$ & $6.6 \times 10^{9}$ & $32.4 \times 10^{6}$
\end{tabular}

E is Young's modulus, $v$ is Poisson's ratio and G is the shear modulus.

Table 2: TSA thermoelastic constants for materials M1 and M2

\begin{tabular}{|c|c|c|c|c|}
\hline Material & $K_{L}$ at $1 \mathrm{~Hz}\left(\times 10^{-6}\right)$ & $K_{T}$ at $1 \mathrm{~Hz}\left(\times 10^{-6}\right)$ & $K_{L}$ at $10 \mathrm{~Hz}\left(\times 10^{-6}\right)$ & $K_{T}$ at $10 \mathrm{~Hz}\left(\times 10^{-6}\right)$ \\
\hline M1 & $1.592 \pm 0.83$ & $3.112 \pm 1.19$ & $0.967 \pm 0.53$ & $3.5 \pm 1.19$ \\
\hline M2 & $1.58 \pm 0.81$ & $2.837 \pm 1.55$ & $0.981 \pm 0.57$ & $3.914 \pm 1.8$ \\
\hline
\end{tabular}

